\title{
PHASE FORMATION AT BONDED VANADIUM AND STAINLESS STEEL INTERFACES
}

\section{T.S.E. Summers}

January 1992

This is an informal report intended primarily for intemal or limited external distribution. The opinions and conclusions stated are those of the author and may or may not be those of the Laboratory.

Work performed under the auspices of the U.S. Department of Energy by the Lawrence Livermore National Laboratory under Contract W-7405-Eng-48.

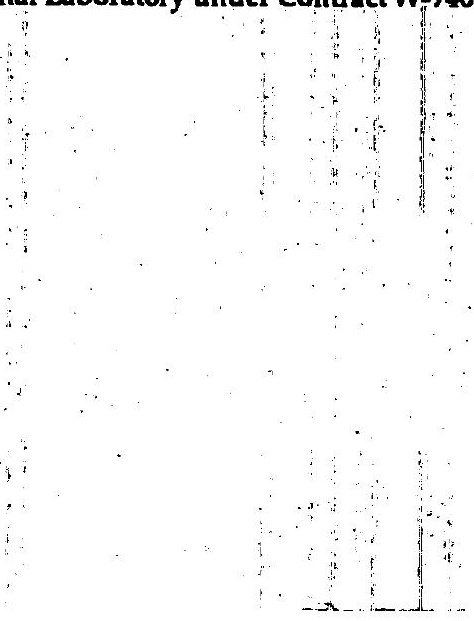




\section{DISCLAIMER}

This report was prepared as an account of work sponsored by an agency of the United States Government. Neither the United States Government nor any agency Thereof, nor any of their employees, makes any warranty, express or implied, or assumes any legal liability or responsibility for the accuracy, completeness, or usefulness of any information, apparatus, product, or process disclosed, or represents that its use would not infringe privately owned rights. Reference herein to any specific commercial product, process, or service by trade name, trademark, manufacturer, or otherwise does not necessarily constitute or imply its endorsement, recommendation, or favoring by the United States Government or any agency thereof. The views and opinions of authors expressed herein do not necessarily state or reflect those of the United States Government or any agency thereof. 


\section{DISCLAIMER}

Portions of this document may be illegible in electronic image products. Images are produced from the best available original document. 


\section{DISCLAIMER}

This document was prepared as an acccount of work sponsored by an agency of the United States Government. Neither the United States Government nor the University of California nor any of their employees, makes any warranty, express or implied, or assumes any legal liability or responsibility for the accuracy, completeness, or usefulness of any information, apparatus, product, or process disclosed, or represents that its use would not infringe privately own rights. Reference herein to any specific commercial products, process, or service by trade name, trademark, manufacturer, or otherwise, does not necessarily constitute or imply its endorsement, recommendation, or favoring by the United States Government or the University of California. The views and opinions of authors expressed herein do not necessarily state or reflect those of the United States Government or the University of California, and shall not be used for advertising or product endorsement purposes.

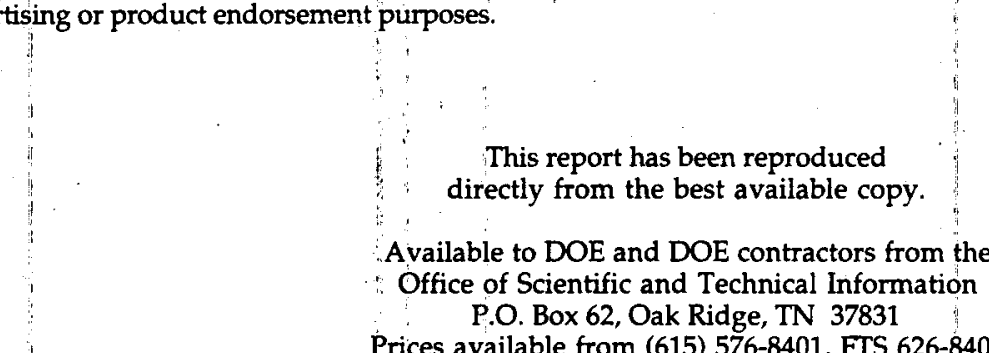

Prices available from (615) 576-8401, FTS 626-8401

Available to the public from the

National Technical Information Service

U.S. Department of Commerce 5285 Port Royal Rd.,

Springfield, VA 22161 
UCRL-ID- -109632

DE92 008984

\title{
Phase Formation at Bonded Vanadium and Stainless Steel Interfaces
}

\author{
T.S.E. Summers
}

\author{
Chemistry and Materials Science Department \\ Materials Division \\ Lawrence Livermore National Laboratory \\ Livermore, CA 94550
}

January 1992

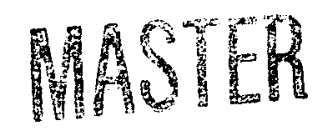




\title{
Phase Formation at Bonded Vanadium and Stainless Steel Interfaces
}

\author{
T.S.E. Summers
}

The interface between vanadium bonded to stainless steel was studied to determine whether a brittle phase formed during three joining operations. Inertia friction welds between $V$ and 21-6-9 stainless steel were examined using TEM. In the aswelded condition, a continuous, polygranular intermetallic layer about $0.25 \mu \mathrm{m}$ thick was present at the interface. This layer grew to about $50 \mu \mathrm{m}$ thick during heat treatment at $1000^{\circ} \mathrm{C}$ for 2 hours. Analysis of electron diffraction patterns confirmed that this intermetallic was the $\sigma$ phase. The interface between vanadium and type 304, SANDVIK SAF 2205, and 21-6-9 stainless steel bonded by a coextrusion process had intermetallic particles at the interface in the as-extruded condition. Heat treatment at $1000^{\circ} \mathrm{C}$ for 2 hours caused these particles to grow into continuous layers in all three cases. Based on the appearance, composition and hardness of this interfacial intermetallic, it was also concluded to be $\sigma$ phase. Bonding V to type 430 stainless steel by co-extrusion caused V-rich carbides to form at the interface due to the higher concentration of $C$ in the type 430 than in the other stainless steels investigated. The carbide particles initially present grew into a continuous layer during a 2-hour heat treatment at $1000^{\circ} \mathrm{C}$. Co-hipping 21-6-9 stainless steel tubing with $\mathrm{V}$ rod resulted in slightly more concentric specimens than the co-extruded ones, but a continuous layer of the $\sigma$ phase formed during the hipping operation. This brittle layer could initiate failure during subsequent forming operations. The vanadium near the stainless steel interface in the coextruded and co-hipped tubing in some cases was harder than before heat treatment and elsewhere in the $\mathrm{V}$ following heat treatment. It was concluded that this hardening was due to thermal straining during cooling following heat treatment and that thermal strains might present a greater problem than seen here when longer tubes are used in actual applications.

\section{INTRODUCTION}

The integrity of the interfaces between vanadium (V) bonded to four different stainless steels was investigated because it was known that the brittle sigma $(\sigma)$ phase sometimes forms in these alloys with high-temperature operations. The four stainless alloys investigated were type 430 which is ferritic, 21-6-9 and type 304 which are austenitic, and SANDVIK SAF 2205 which is a duplex alloy containing both ferrite and austenite in amounts depending on the processing. Typical compositions for these stainless alloys are given in Table 1.

Generally, formation of $\sigma$ phase takes long exposures to elevated temperatures. However, various elements and cold work can accelerate its formation. These $\sigma$-forming elements are also typically ferrite stabilizers and include $\mathrm{Cr}, \mathrm{Si}, \mathrm{Mo}, \mathrm{W}, \mathrm{V}, \mathrm{Ti}$ and $\mathrm{Nb}$ $[1,3]$. Formation of $\sigma$ phase is especially common in the ferritic stainless steels, and sigma is more likely to form in austenitic alloys when there is ferrite retained from hightemperature operations [1,3]. Vanadium is known to be a ferrite forming element [3], and it forms $\sigma$ phase with many elements [4,5]. It may, thus, be expected to promote $\sigma$ in the stainless steel alloys at least under certain processing and/or service conditions. 
Table 1

Nominal Compositions for the Stainless Steel Alloys Investigated [1,2]

\begin{tabular}{|c|c|c|c|c|c|}
\hline Sample & $\mathrm{Fe}$ & $\mathrm{Cr}$ & $\mathrm{Ni}$ & $\mathrm{Mn}$ & Other \\
\hline $\begin{array}{l}\text { Sandvik SAF } \\
2205 \text { Duplex }\end{array}$ & $\mathrm{Bal}$ & 22 & 5.5 & $2.0 \max$ & $\begin{array}{c}3.0 \mathrm{Mo} \\
0.14 \mathrm{~N} \\
.03 \max \mathrm{C} \\
0.8 \max \mathrm{Si} \\
.02 \max \mathrm{S}\end{array}$ \\
\hline Type 304 & Bal & $18-20$ & $8-10.5$ & $2 \max$ & $\begin{array}{l}.08 \max \mathrm{C} \\
.045 \max \mathrm{P} \\
.03 \max \mathrm{S}\end{array}$ \\
\hline $21-6-9$ & Bal & $19-21.5$ & $5.5-7.5$ & $8-10$ & $\begin{array}{l}.2-.25 \mathrm{~N} \\
.02-.04 \mathrm{C} \\
.01-.1 \mathrm{Al} \\
.5 \operatorname{max~Si} \\
.015 \max \mathrm{S} \\
.02 \max \mathrm{P} \\
\end{array}$ \\
\hline Type 430 & Bal & $14-15$ & & $1 \max$ & $\begin{array}{l}.12 \max C \\
.04 \max P \\
.03 \max S\end{array}$ \\
\hline
\end{tabular}

Sigma is a complicated phase with a tetragonal structure and 30 atoms per unit cell [3, 6]. It is very brittle and has reported hardnesses as high as $R_{c} 68(-940 \mathrm{DPH})$ [3].

\section{EXPERIMENTAL}

Vanadium rod was co-extruded with tubing made of the four stainless steels listed in Table 1 above using a proprietary process at Nuclear Metals, Inc. In addition, 21-6-9 stainless steel tubing was co-hipped with vanadium rod. Extrusion is an attractive process for bonding because shearing of the metal surfaces exposes clean metal at the surfaces to be bonded. Also, short times are required which limits the thickness of the interfacial reaction layer. Hipping was also investigated as a possible method for producing more concentric tubing. Both of these processes resulted in a central $\mathrm{V}$ rod about $4 \mathrm{~mm}$ in diameter bonded to and surrounded by a stainless steel tube with about 1 to $1.5 \mathrm{~mm}$ thickness. A $2.5 \mathrm{~mm}$ hole was drilled in the center of each of the co-extruded specimens.

For the purpose of interface characterization after a relatively rapid bonding process, approximately 7-mm V and 9-mm 21-6-9 stainless steel rods were bonded by an inertia friction welding process at Manufacturing Technology, Inc. in South Bend, Indiana. This bonding was done in 10-20 seconds but resulted in some localized melting at the interface. All of the above specimens were examined in the as-bonded condition and after heat treatment at $1000^{\circ} \mathrm{C}$ for 2 hours. 


\section{RESULTS}

\subsection{Concentricity of Extruded and Hipped Tubes}

Vanadium and stainless steel tubing thickness measurements were made from low magnification optical micrographs of polished transverse cross sections. These measurements were made at eight equally spaced positions separated by $45^{\circ}$ around the tube. The results are plotted in Figure 1 for both the co-extruded and the co-hipped specimens. In this figure, the difference in millimeters between the maximum and minimum thicknesses measured are plotted.

\subsection{Microstructures}

\subsubsection{Inertia Friction Welded V and Stainless Steel}

The inertia friction welded rods were examined using TEM. TEM specimen discs were extracted from the V/stainless steel interface so that a length of the interface as viewed in cross section was contained across the center of the disc. Specimens were thinned at the interface to electron transparency by conventional techniques. The interface of an as-welded specimen is shown in Figure 2. A continuous, polygranular interfacial layer approximately $.25 \mu \mathrm{m}$ thick formed during welding. The grains were equiaxed with diameters approximately equal to the layer thickness. Small voids approximately $.05 \mu \mathrm{m}$ in diameter were also present at the interface. These voids are possibly due to gasses trapped during welding or to vacancy coalescence following welding.

During heat treatment for 2 hours at $1000^{\circ} \mathrm{C}$, the interfacial layer thickened dramatically to approximately $50 \mu \mathrm{m}$. Again this layer was polygranular with a large grain size averaging about $20-30 \mu \mathrm{m}$ in diameter.

\subsubsection{Co-extruded V and Stainless Steel Tubing}

Typical as-extruded $V$ and stainless steel microstructures are shown in Figure 3. Both the $V$ and the stainless steels were highly deformed with a grain structure elongated in the extruding direction. After heat treatment at $1000^{\circ} \mathrm{C}$ for 2 hours, the $\mathrm{V}$ and stainless steel in all four cases had recrystallized. Representative heat treated microstructures are shown in Figure 4.

In all four samples, discrete particles were present at the $\mathrm{V} / \mathrm{stainless}$ steel interface in the as-extruded condition. The particles were rather small, but, as shown in Figure 5, they were largest in the 304 specimen. After heat treatment at $1000^{\circ} \mathrm{C}$, the particles grew into the more or less continuous layers shown if Figure 6.

\subsubsection{Co-hipped V and Stainless Steel Tubing}

During hipping, the vanadium and the 21-6-9 stainless steel both recrystallized. An example of the $\mathrm{V}$ microstructure typical of all three specimens is shown in Figure 7. Also shown in this figure, a continuous, double interfacial layer about $8 \mu \mathrm{m}$ thick formed in these specimens during the hipping operation. After heat treatment at $1000^{\circ} \mathrm{C}$ for 2 hours, 
this double layer grew to about $20 \mu \mathrm{m}$ in thickness as shown in Figure 8. The vanadium grain size, shown in Figure 8 as well, appears to be fairly stable with this heat treatment.

\subsection{Microprobe}

\subsubsection{Microprobe Traces}

Results from typical microprobe scans are shown in Figure 9. Traces across the $\mathrm{V} /$ stainless steel interfaces in the as-extruded samples showed that $\mathrm{V}$ had diffused into the steels over a distance of about 20-30 $\mu \mathrm{m}$. Relatively little of the stainless steel constituents were seen to diffuse into the $\mathrm{V}$. In all four cases, Fe appears to have diffused into the $\mathrm{V}$ about 5-10 $\mu \mathrm{m}$ while in the duplex alloy, $\mathrm{Cr}$ also diffused about $5 \mu \mathrm{m}$ into the $\mathrm{V}$.

During the $1000^{\circ} \mathrm{C}, 2$-hour heat treatment of the V/type 430 stainless steel sample, an $\mathrm{V} / \mathrm{Fe} / \mathrm{Cr}$-rich layer about $20 \mu \mathrm{m}$ thick formed at the $\mathrm{V} /$ steel interface. The amount of $\mathrm{Cr}$ and $\mathrm{Fe}$ increased in moving toward the stainless. Beyond that, $\mathrm{V}$ had diffused into the steel over a distance of about $60 \mu \mathrm{m}$ where at a given distance from the interface, the $\mathrm{V}$ concentration was about five times its value in the as-extruded condition. The heat treated duplex sample showed a similar profile with an approximately $15 \mu \mathrm{m}$ thick $\mathrm{V}-\mathrm{Fe}-\mathrm{Cr}-\mathrm{Ni}$ interfacial layer and diffusion of $\mathrm{V}$ into the steel over a distance of about $75 \mu \mathrm{m}$. The sum of the concentrations measured in the 430 sample near the interface was somewhat less than $100 \%$ indicating the presence of an element which was not accounted for. As discussed below, this missing element is $\mathrm{C}$.

The two heat treated austenitic stainless steel samples had slightly different composition profiles across the $\mathrm{V} /$ steel interface. Again, there was a V-Fe-Cr-Ni layer about $20 \mu \mathrm{m}$ thick in the 21-6-9 sample and about $10 \mu \mathrm{m}$ wide in the 304 sample. The $\mathrm{V}$ profile in these cases, however, was different. The concentration of $\mathrm{V}$ decreased only slightly. over a distance of about $50 \mu \mathrm{m}$ into the 21-6-9 and the type 304 stainless steels. Beyond that, the V concentration dropped sharply.

\subsubsection{Selected Area Microprobe Analysis}

The results of point mode microprobe analysis are displayed in Table 2 . There, the samples are identified by the steel used and by their condition (i.e. AE or as extruded and $\mathrm{HT}$ or heat treated at $1000^{\circ} \mathrm{C}$ for $2 \mathrm{hr}$ ). The sum of the element concentrations in the case of the $\mathbf{4 3 0}$ sample was quite low. In that sample, the interfacial phase which formed was found to contain much more $C$ than was found elsewhere in the sample. No quantitative measurement of the $\mathrm{C}$ content was made.

\subsection{Hardness Traces}

The microhardness traces for the co-extruded samples are shown in Figure 10. In all cases, the data points shown represent 3-6 measurements for the heat treated samples and generally one measurement for the as-extruded samples. Measurements yielding unusually low or high values in the as-extruded samples were repeated three times. Figure 3.4.2 shows similar data for the co-hipped specimens. Again, measurements for the heat treated specimens were repeated 3-6 times. 
Table 2

Results (in wt.\%) of Microprobe Analysis

\begin{tabular}{|c|c|c|c|c|c|c|c|c|}
\hline Sample & Area* & $\mathrm{Cr}$ & $\mathrm{Fe}$ & $\mathrm{Ni}$ & V & $\mathrm{Mn}$ & Mo & Total \\
\hline $430 \mathrm{AE}$ & Small Particles in Steel & 32.46 & 58.54 & 0.39 & 0.84 & 0.48 & 0.00 & 92.71 \\
\hline $430 \mathrm{AE}$ & Small Particles in Steel & 39.27 & 50.71 & 0.35 & 1.19 & 0.44 & 0.00 & 91.96 \\
\hline $430 \mathrm{AE}$ & Interfacial Particle & 4.38 & 3.62 & 0.04 & 73.93 & 0.09 & 0.00 & 82.05 \\
\hline $430 \mathrm{HT}$ & Interfacial Phase (Nearest V) & 2.02 & $\overline{0.24}$ & 0.05 & 86.68 & 0.00 & 0.00 & 88.99 \\
\hline $430 \mathrm{HT}$ & Interfacial Phase & 8.98 & 3.96 & 0.07 & 74.20 & 0.05 & 0.00 & 87.26 \\
\hline $430 \mathrm{HT}$ & Interfacial Phase (Nearest 430) & 14.93 & 9.68 & 0.10 & 62.18 & 0.12 & 0.00 & 87.01 \\
\hline $430 \mathrm{HT}$ & Steel near Interfacial Phase & 12.22 & 69.75 & 0.59 & 16.38 & 0.48 & 0.00 & 99.42 \\
\hline $430 \mathrm{HT}$ & Steel in Single-Phase Band & 17.95 & 79.16 & 0.60 & 0.07 & 0.57 & 0.00 & 98.35 \\
\hline $430 \mathrm{HT}$ & $\begin{array}{l}\text { Phase with Light Contrast in 2- } \\
\text { phase Bulk }\end{array}$ & 16.80 & 78.79 & 0.76 & 0.06 & 0.63 & 0.00 & $\overline{97.04}$ \\
\hline $21-6-9 \mathrm{HT}$ & Bulk Steel & 19.68 & 61.16 & 6.59 & 0.07 & 9.34 & 0.00 & 96.84 \\
\hline $21-6-9 \mathrm{HT}$ & Interfacial Phase Near V & 18.17 & 48.25 & 5.38 & 17.57 & 7.79 & $\overline{0.00}$ & 97.15 \\
\hline $21-6-9 \mathrm{HT}$ & Interfacial Phase Near steel & 19.04 & 56.42 & 5.55 & 7.35 & 8.59 & 0.00 & 96.94 \\
\hline $21-6-9$ HT & $\begin{array}{c}\text { Interfacial Phase in steel grain } \\
\text { boundaries }\end{array}$ & 20.16 & 57.21 & 5.61 & 5.27 & 8.96 & 0.00 & 97.22 \\
\hline $21-6-9 \mathrm{HT}$ & Dark Interfacial Phase & 19.52 & 57.36 & 5.82 & 5.80 & 8.88 & 0.00 & 97.38 \\
\hline $304 \mathrm{AE}$ & Bulk Steel & 18.40 & 68.21 & 8.34 & 0.13 & 1.18 & 0.00 & 96.25 \\
\hline $304 \mathrm{AE}$ & Interfacial Particle & 19.72 & 55.21 & 5.76 & 15.43 & 0.93 & $\overline{0.16}$ & 97.21 \\
\hline $304 \mathrm{HT}$ & Interfacial Phase & 12.59 & 49.08 & 7.20 & 28.68 & 0.80 & 0.00 & 98.35 \\
\hline $304 \mathrm{HT}$ & Dark Interfacial Band & 18.42 & 62.75 & 7.11 & 8.56 & 1.11 & 0.00 & 97.96 \\
\hline $304 \mathrm{HT}$ & Bulk 304 & 19.05 & 68.91 & 8.34 & 0.14 & 1.19 & 0.01 & 97.64 \\
\hline Duplex AE & Light Particles in Bulk Steel & 29.17 & 57.43 & $3 . \overline{07}$ & 0.09 & 1.51 & 7.64 & 98.92 \\
\hline Duplex AE & Bulk Steel & 20.33 & 67.48 & 6.45 & 0.07 & 1.71 & 1.73 & 97.77 \\
\hline Duplex HT & $\begin{array}{l}\text { Phase with Light Contrast in 2- } \\
\text { phase Bulk }\end{array}$ & 23.82 & 65.24 & 4.62 & 0.07 & 1.54 & 2.68 & 97.96 \\
\hline Duplex HT & $\begin{array}{l}\text { Phase with Dark Contrast in 2- } \\
\text { phase Bulk }\end{array}$ & 24.16 & 65.64 & 4.01 & 0.07 & 1.50 & 2.59 & 97.97 \\
\hline Duplex HT & Dark Interfacial Band & 22.01 & 63.68 & 4.68 & 2.96 & 1.54 & 2.19 & 97.06 \\
\hline Duplex HT & Light Interfacial Phase & 17.02 & 49.98 & 4.38 & 23.82 & 1.19 & 2.64 & 99.03 \\
\hline
\end{tabular}

*See Figures 5 and 6 


\section{DISCUSSION}

\subsection{Tubing Concentricity}

The results of the co-extruded $\mathrm{V}$ and stainless steel tubing concentricity measurements are displayed in Figure 1. The values plotted correspond to the maximum difference between measurements made at eight equally spaced angular positions around the specimens. No difference in the measured concentricity due to heat treatment is expected. Any differences seen are likely to be due to differences in concentricity at different locations along the tube lengths. The maximum variation (i.e. the difference between the largest and the smallest measured values) in the total thickness around the bimetal tubes is an indication of the degree to which the hole, which was drilled into the tubes after the coextrusion process, is centered. For most of the specimens, this value is less than 0.10$0.15 \mathrm{~mm}$ which is within reasonable machining tolerances. For a concentric V/stainless steel specimen, the maximum variation in thickness around the steel tube should be fairly low while variation in the $V$ thickness should be similar to that of the total thickness. Only two specimens show this pattern: the as-extruded 304 and the heat treated duplex specimens.

For samples in which the central hole is centered well but the $V$ and stainless steel tubes are not concentric, the maximum variation in the total thickness would be low, but that of the V and stainless steel would be high. An example of this case would be for the heat treated 430 sample. Other patterns in Figure 1 are due to nonuniform deformation resulting in noncircular cross sections. Comparison of the as-extruded and heat treated samples shows that the degree of concentricity varies somewhat along the length of the specimen.

The results of the co-hipped V and 21-6-9 stainless steel tubing concentricity measurements are also displayed in Figure 1. Concentricity in the co-extruded and cohipped samples is comparable. The limited data for the co-hipped specimens, however, suggest that co-hipping may be slightly better.

\subsection{Microhardness}

Microhardness measurements were made within the intermetallic layers in the samples of $\mathrm{V}$ co-extruded with $21-6-9,304$ and the duplex stainless steel heat treated at $1000^{\circ} \mathrm{C}$ for 2 hours. These measurements were very difficult to make without cracking the intermetallic suggesting that it is very brittle. The Vickers hardness values obtained ranged from 800 to 1000 depending on the extent of cracking and the proximity of the indent to the adjacent, relatively soft $\mathrm{V}$ or stainless steel. The extreme brittleness and hardness of these intermetallic layers are consistent with their being the $\sigma$ phase.

The $V$ and the steel of the extruded samples were not recrystallized in the as-extruded condition. Heat treatment at $1000^{\circ} \mathrm{C}$ for 2 hours, however, was sufficient to cause recrystallization in all four cases. This recrystallization is evident as a drop in the hardness shown in Figure 10 following heat treatment for all the stainless steels except the type 430 sample which had an unusual, three-phase microstructure as discussed below. The hipping process occurred at a temperature sufficient to cause recrystallization. As a result, 
the microhardness values shown in Figure 11 for the co-hipped specimens do not change significantly with heat treatment.

The microhardness values measured across the stainless tubing cross sections in both the co-extruded and co-hipped samples was essentially constant while the values across the $\mathrm{V}$ cross sections increased in moving toward the stainless interface in some cases after heat treatment as shown in Figures 10 and 11. This increase in hardness is not a result of contributions from the relatively hard interfacial $\sigma$ layer as no indents closer than two indent diameters to the interface were included in the averages, and the hardening effect extended well beyond that distance. This hardening of the $\mathrm{V}$ near the interface is probably a result of thermal straining on cooling from the heat treatment temperature. In support of this argument, the co-extruded samples of 21-6-9 and Duplex stainless steels and the cohipped samples which were made of 21-6-9 stainless steel show the greatest nearinterfacial $\mathrm{V}$ hardening and also have the largest thermal expansion coefficient mismatch with $\mathrm{V}$ as shown in Table 3. Vanadium near the the heat treated 21-6-9 and duplex interfaces also appeared to be more deformed than further into the $V$ tube (see Figure 4). The concentration of plastic deformation due to thermal straining in the $\mathrm{V}$ rather than in the stainless steels is most likely due to the greater stiffness, strength and thickness of the stainless steel tubes used.

Table 3

Thermal Expansion Coefficients $\left(10^{-6} / \mathrm{C}\right)$ for the Materials Studied $[1,2,7]$

\begin{tabular}{|c|c|c|c|}
\hline Material & $20^{\circ} \mathrm{C}$ & $500^{\circ} \mathrm{C}$ & $1000^{\circ} \mathrm{C}$ \\
\hline \hline 430 & $5.7^{*}$ & 5.8 & 6.7 \\
\hline $21-6-9$ & 16.6 & 20.6 & 24.4 \\
\hline 304 & 9.6 & 9.8 & 10.5 \\
\hline Sandvik SAF 2205 Duplex & $13.7\left(20-100^{\circ} \mathrm{C}\right)$ & $14.7\left(20-300^{\circ} \mathrm{C}\right)$ & \\
\hline V & 8.4 & 10.9 & 13.6 \\
\hline
\end{tabular}

*extrapolated from values at $200^{\circ} \mathrm{C}$

\subsection{Interfacial Phases}

\subsubsection{Inertia Friction Welds}

The interfacial phase in the as-welded and heat treated specimens was identified using electron diffraction in TEM. In each case, two low-order zone axis patterns separated by a know solid angle tilt were taken from a typical, isolated grain of the interfacial phase and compared to calculated patterns. A sample diffraction pattern and the corresponding spacings, both measured and calculated, are given in the Appendix. The measured spacings from diffracted spots were within $2 \%$ of spacings calculated based on the sigma phase. The measured angle of tilt between the two zone axes was well within the limit of accuracy at about $1 \%$ of calculated values. It was therefore concluded that the interfacial phase in the inertia friction welded specimens was the $\sigma$ phase. 
The inertia friction welding process is very rapid taking only about 10-15 seconds, and it is surprising that a continuous layer of $\sigma$ phase (Figure 2) has time to form during this operation. During this welding process, however, a thin film of material melted. It is possible that mixing of the $\mathrm{V}$ and elements in the stainless steels occurs more quickly in the liquid state so that the $\sigma$ phase can form more rapidly than is typical of stainless steels especially when $\mathrm{V}$ is not present.

\subsubsection{Co-Extruded Specimens}

In backscatter images, the particles at the interface of the as-extruded 430 sample and the interfacial layers of the heat treated sample were darker than either the $V$ or the steel which is surprising if this phase formed from the phases on either side. Vanadium is the lightest element which was supposed to be present in the system, and it should have the darkest contrast in a backscattered electron image. Microprobe analysis showed that these particles, at least in the heat treated condition (the particles in the as-extruded condition were too small to analyze), consisted mainly of $\mathrm{V}$ adjacent to the $\mathrm{V}$ side of the interface with increasing amounts of $\mathrm{Cr}$ and $\mathrm{Fe}$ in moving toward the stainless steel as shown in Table 2. Although no quantitative values could be obtained, the analysis also showed that a significant amount of $C$ was present. This data then suggests that the interfacial particles in this case are carbides. The presence of the very light element $C$ would thus explain the dark contrast seen for these particles in the backscattered electron image. As discussed below, the carbon to form these carbides likely came from the 430 stainless steel.

The other three samples had particles in the as-extruded condition and intermetallic layers after heat treatment at $1000^{\circ} \mathrm{C}$ for 2 hours that were lighter in contrast than either the $\mathrm{V}$ or steel. This light contrast is presumably due to phase structure rather than the presence of a higher concentration of a heavier element. After heat treatment in all three cases, the normalized compositions obtained using the three elements with highest composition in this intermetallic layer, when there are mainly three elements $(\mathrm{Cr}-\mathrm{Fe}-\mathrm{V})$ present (see Table 4), fall well within the $\sigma$ phase field of the $900^{\circ} \mathrm{C}$ isotherm $\left(1000^{\circ} \mathrm{C}\right.$ isotherm not available) of the $\mathrm{Cr}-\mathrm{Fe}-\mathrm{V}$ ternary phase diagram as shown in Figure 12. In the as-extruded 304 sample, the normalized $\mathrm{Cr}-\mathrm{Fe}-\mathrm{V}$ composition of the interfacial particles also falls within the $\sigma$ phase field at $900^{\circ} \mathrm{C}$ as well as at $427^{\circ} \mathrm{C}$ (the lowest isotherm available) [8]. The particles in the other two as-extruded samples were too small to analyze.

In the heat treated 21-6-9 sample, the intermetallic layer was more complicated than those of the other samples. As discussed above, the layer adjacent to the $\mathrm{V}$ consisted mainly of $\mathrm{Cr}, \mathrm{Fe}$ and $\mathrm{V}$. The normalized three-component composition of this layer fell within the $\sigma$ phase field at $900^{\circ} \mathrm{C}$. In moving through this layer toward the 21-6-9 stainless, the $\mathrm{V}$ concentration decreases. At the outer regions near the stainless, the intermetallic layer consisted mostly of $\mathrm{Fe}$ and $\mathrm{Cr}$, but the remaining three elements, $\mathrm{V}, \mathrm{Ni}$ and $\mathrm{Mn}$, had about the same concentration. No five-element phase diagrams for this system are available, and normalizing for three elements when there are not three major elements present is not likely to yield very useful results. With that in mind, using the three major components, $\mathrm{Cr}, \mathrm{Fe}$ and $\mathrm{Mn}$ or using $\mathrm{Cr}, \mathrm{Fe}$ and $\mathrm{V}$ yields normalized compositions within the bcc $\alpha$ Fe phase field of the respective phase diagrams. The first layer adjacent to the $\mathrm{V}$, however, also fits within the $\alpha \mathrm{Fe}$ phase field when the percent $\mathrm{Cr}$, 
Fe and $\mathrm{Mn}$ are used. It appears that $\mathrm{V}$ is a strong $\sigma$ former, and it is reasonable to assume that the normalized $\mathrm{Cr}-\mathrm{Fe}-\mathrm{Mn}-\mathrm{V}$ composition would fall within the $\sigma$ phase field if a quaternary phase diagram were available. Further into the steel the white intermetallic phase forms on steel grain boundaries. The composition of these white regions is very similar to that of the second layer discussed above with slightly less V. It is therefore assumed to be $\sigma$ as well and appears to nucleate more easily at the grain boundaries.

Table 4

Microprobe Results (wt. \%) Normalized Using Three Major Components

\begin{tabular}{|c|c|c|c|c|c|c|c|c|}
\hline Sample/Condition & $\mathrm{Cr}$ & $\mathrm{Fe}$ & $\mathrm{Ni}$ & $\mathrm{V}$ & $\mathrm{Mn}$ & Mo & Total & Comments \\
\hline $304 \mathrm{AE}$ & $\begin{array}{l}19.72 \\
19.72 \\
21.82 \\
19.72 \\
24.44 \\
\end{array}$ & $\begin{array}{l}55.21 \\
55.21 \\
55.21 \\
68.42 \\
\end{array}$ & $\begin{array}{r} \\
5.76 \\
7.14 \\
\end{array}$ & $\begin{array}{l}15.43 \\
15.43 \\
17.08\end{array}$ & .93 & .16 & $\begin{array}{l}97.21 \\
90.36 \\
100.0 \\
80.69 \\
100.0 \\
\end{array}$ & $\begin{array}{c}\text { Interfacial Particle } \\
3 \text { Major Elements } \\
3 \text { Normalized } \\
2 \text { Major+4th Major } \\
\text { Normalized }\end{array}$ \\
\hline 304 HT & $\begin{array}{l}12.59 \\
12.59 \\
13.93 \\
\end{array}$ & $\begin{array}{l}49.08 \\
49.08 \\
54.32 \\
\end{array}$ & 7.20 & $\begin{array}{l}28.68 \\
28.68 \\
31.74 \\
\end{array}$ & 0.80 & 0.00 & $\begin{array}{l}98.35 \\
90.35 \\
100.0 \\
\end{array}$ & $\begin{array}{c}\text { Interfacial Phase } \\
3 \text { Major Elements } \\
\text { 3 Normalized }\end{array}$ \\
\hline 21-6-9 HT & $\begin{array}{l}18.17 \\
18.17 \\
21.63 \\
18.17 \\
24.48 \\
\end{array}$ & $\begin{array}{l}48.25 \\
48.25 \\
57.45 \\
48.25 \\
65.02 \\
\end{array}$ & 5.38 & $\begin{array}{l}17.57 \\
17.57 \\
20.92\end{array}$ & $\begin{array}{c} \\
7.79 \\
10.50\end{array}$ & 0.00 & $\begin{array}{l}97.15 \\
83.99 \\
100.0 \\
74.21 \\
100.0 \\
\end{array}$ & $\begin{array}{l}\text { Interfacial Phase } \\
\text { Adjacent to V } \\
3 \text { Major Elements } \\
3 \text { Normalized } \\
2 \text { Major+4th Major } \\
\text { Normalized }\end{array}$ \\
\hline 21-6-9 HT & $\begin{array}{l}19.04 \\
19.04 \\
22.65 \\
19.04 \\
22.99\end{array}$ & $\begin{array}{l}56.42 \\
56.42 \\
67.13 \\
56.42 \\
68.13 \\
\end{array}$ & 5.55 & $\begin{array}{r}7.35 \\
8.88 \\
\end{array}$ & $\begin{array}{c}8.59 \\
8.59 \\
10.22\end{array}$ & 0.00 & $\begin{array}{l}96.94 \\
84.05 \\
100.0 \\
83.81 \\
100.0\end{array}$ & $\begin{array}{l}\text { Interfacial Phase } \\
\text { Adjacent to 21-6-9 } \\
3 \text { Major Elements } \\
3 \text { Normalized } \\
2 \text { Major+4th Major } \\
\text { Normalized }\end{array}$ \\
\hline 21-6-9 HT & $\begin{array}{l}20.16 \\
20.16 \\
23.35 \\
20.16 \\
24.39 \\
\end{array}$ & $\begin{array}{l}57.21 \\
57.21 \\
66.27 \\
57.21 \\
69.23 \\
\end{array}$ & 5.61 & $\begin{array}{l}5.27 \\
6.28 \\
\end{array}$ & $\begin{array}{l}8.96 \\
8.96 \\
10.4\end{array}$ & 0.00 & $\begin{array}{l}97.22 \\
86.33 \\
100.0 \\
82.64 \\
100.0 \\
\end{array}$ & $\begin{array}{c}\text { Intermetallic on 21- } \\
6-9 \text { grain boundaries } \\
3 \text { Major Elements } \\
3 \text { Normalized } \\
2 \text { Major+4th Major } \\
\text { Normalized }\end{array}$ \\
\hline
\end{tabular}

In both the heat treated 21-6-9 and 304 samples, the steel regions adjacent to the intermetallic show up with dark contrast in the backscattered electron images. The 
microprobe data of Table 2 shows that in the case of 304, this band has about the same composition as the bulk 304 , but wit more $V$ which may account for the dark contrast. In the 21-6-9 sample, the dark band has a composition similar to the surrounding $\sigma$ phase but with less V. In the heat treated 21-6-9 sample, growth of the $\sigma$ phase into this layer is more advanced than it is in the 304 sample which might account for it having a composition more similar to the $\sigma$ than to the bulk 21-6-9. In both cases, it appears that $V$ diffuses into the region during the heat treatment. In the case of 21-6-9, $\sigma$ can nucleate on the grain boundaries on the steel side of this V-rich band even though there is less V present there. Nucleation of sigma elsewhere in the band, however, can only occur once enough $\mathrm{V}$ has diffused in.

\subsubsection{Co-Hipped Specimens}

The interface of the co-hipped V/21-6-9 stainless steel specimens was optically similar to the heat treated co-extruded V/austenitic stainless steel specimens: a double layer with a hard phase with light contrast forming adjacent to the $\mathrm{V}$ and a darker, softer layer forming adjacent to the steel. The hard, light layer adjacent to the $V$ was therefore concluded to be the $\sigma$ phase. After hipping, a continuous layer has already formed and grows during the heat treatment. The more rapid $\sigma$ formation in the hipped specimens than in the extruded ones is no doubt due to the higher temperatures and longer times associated with the hipping process.

\subsection{Co-extruded Samples}

\subsection{1. $430 / \mathrm{V}$ Samples}

Microprobe analysis of the interfacial particles in the as-extruded condition could not be done due to their small size. Their contrast in backscattered electron imaging, however, suggests that they are carbides similar to the interfacial carbide phase present to a greater extent following heat treatment. The carbon to form these carbides probably comes from the steel itself as is evident from the microstructural changes occurring in the steel with heat treatment as discussed below.

Well removed from the $V$ interface in the 430 stainless steel, a multi-phase microstructure exists. Comparison of Figures 3 and 4 indicates that while the stainless steel had recrystallized during the heat treatment, the grain size had remained quite small. The fact that the grain size was very fine in the heat treated condition implies that a twophase microstructure existed at $1000^{\circ} \mathrm{C}$. Type 430 stainless steel is essentially an Fe-Cr binary alloy (Table 1) and microprobe analysis confirmed this (Table 2). Also shown in Table 1, the maximum allowable $\mathrm{C}(0.12 \mathrm{wt} . \%)$ in this alloy is higher than any of the others used. The $1000^{\circ} \mathrm{C}$ isotherm of the $\mathrm{C}-\mathrm{Cr}$-Fe phase diagram in Figure 13 shows that relatively little $\mathrm{C}$, less than .1\%, is needed to stabilize austenite in an $\alpha+\gamma$ two-phase region at $1000^{\circ} \mathrm{C}$. It is this two-phase structure which likely keeps the grains from growing significantly during heat treatment. Upon cooling to room temperature, the austenite becomes unstable and appears to transform to ferrite + some carbide phase [8]. The resultant structure is shown in Figure 14. The darker grains are the transformed 
austenite grains and appear to be made up of a lamellar distribution of ferrite and a carbide phase.

In a band about $650 \mu \mathrm{m}$ thick adjacent to the $\sigma$ layer in the heat treated sample, only one phase is present in the steel (Figure 4). The grains in this region have grown to much larger sizes than elsewhere in the steel. It appears that $C$ diffuses from this region to the interface to interact with $\mathrm{V}$ which is a strong carbide former. The local depletion of $\mathrm{C}$ in this region causes the austenite to become unstable at $1000^{\circ} \mathrm{C}$ so that only ferrite is present during the heat treatment. Because the structure now consists of only one phase, the grains grow quite large during heat treatment and remain $\alpha$ during cooling. Because this large-grained, single-phased band at the interface in the steel is so large, it is much more likely that ferrite stabilization during heat treatment was due to $\mathrm{C}$ diffusion out of the area rather than $\mathrm{V}$ diffusion into it. Carbon as a small interstitial impurity can diffuse over much greater distances than $\mathrm{V}$, and microprobe traces across the interface indicated that $\mathrm{V}$ had only diffused into the stainless about $60 \mu \mathrm{m}$. The presence of carbon in the steel is also consistent with the microstructure seen throughout the rest of the steel and with the presence of carbides at the interface.

\subsection{2. $21-6-9 / \mathrm{V}$ and $304 / \mathrm{V}$ Samples}

Following heat treatment, both of the austenitic alloys have characteristic recrystallized microstructures as shown if Figure 4. As seen in Figure 6, adjacent to the continuous interfacial layer of $\sigma$ phase, a band of material with contrast intermediate between the $V$ and the stainless alloys in backscattered electron imaging forms. The microprobe data of Table 2 shows that the composition of this band is similar to that of the adjacent $\sigma$ phase but lower in V. The microhardness data shown in Figure 10 indicates that this band is harder than the adjacent steel but much softer than the $\sigma$ phase. There are too many elements present to clearly identify this phase on a phase diagram, but both the intermediate hardness and contrast can be explained simply by the fact that $\mathrm{V}$ has diffused into the region. The austenite would then be darker due to the presence of the relatively light element, $\mathrm{V}$, and it would be harder due to solid solution strengthening. If that were the explanation, though, it is striking that the distance over which $\mathrm{V}$ has diffused into an untransformed structure is as uniform as it is in Figure 6. In addition, this dark phase can also be seen at grain boundary triple points in the steel very near the dark band of these alloys suggesting that $\mathrm{V}$, at least initially, diffuses along the steel grain boundaries. It is also possible that this dark phase is a precursor to the sigma phase which does not form as easily in austenitic stainless steels as it does in ferritic ones. The formation of a sigma precursor has recently been discussed by Gavrilyuk et al. [9] and Naohara and Shinohara [10].

\subsubsection{Duplex/V Samples}

Both the $\mathrm{V}$ and stainless steel in this sample recrystallize following heat treatment at $1000^{\circ} \mathrm{C}$ for 2 hours. The resultant two-phase $\alpha+y$ microstructure coarsens very little during the heat treatment as is evident in Figures 4 and 6 . The microprobe results shown in Table 2 suggest that the two phases (with light and dark contrast in backscattered electron imaging) have similar compositions. Their similarities, however, may be due to 
the relatively small grain size and sampling from both phases during microprobe analysis. The results showed that the darker phase has slightly more $\mathrm{Cr}$ and less $\mathrm{Ni}$ than the lighter phase suggesting that it is ferrite while the lighter phase is austenite.

Adjacent to the $\sigma$ layer which forms during heat treatment at the interface, a singlephase band of large grains forms similar to the 430 sample but much smaller in width. These grains have dark contrast in a backscattered electron image and as reasoned above are probably ferrite. The microprobe results indicated that this band had a composition similar to the bulk steel except for a greater amount of $\mathrm{V}$ which is a ferrite stabilizer. The microprobe trace across the interface showed that $\mathrm{V}$ had diffused into the stainless over a distance of about $50 \mu \mathrm{m}$, and the micrograph of Figure 6 shows it to be about $50-60 \mu \mathrm{m}$. The width here of the single-phase band is much smaller than the 430 sample, but similar to the 430 sample, the ferrite phase is stabilized (in this case by diffusion of $\mathrm{V}$ into the steel) and can grow to rather large grain sizes without the constraining austenite. The microhardness trace of Figure 10 suggests that this single-phased band is harder than the remaining steel, but this apparent hardness may simply be due to contributions from the adjacent sigma layer. Because the band is fairly thin, a microhardness indent well removed from the $\sigma$ phase could not be made within it. Microhardness measurements immediately outside this region in the steel are softer than elsewhere in the steel suggesting that contributions from the dark band cause the measured value to be lower assuming the dark band is actually softer than the two-phase steel regions. Also, the presence of $V$ in the two-phase steel regions adjacent to the single-phase band will cause there to be less austenite at $1000^{\circ} \mathrm{C}$ than there is in regions where there is no $\mathrm{V}$ so that the grain size locally can grow to slightly larger values during heat treatment.

\section{CONCLUSIONS}

The sigma phase was identified using electron diffraction at the interface of inertia friction welded V and 21-6-9 stainless steel rods in the as-welded condition and after heat treatment for 2 hours at $1000^{\circ} \mathrm{C}$. In this system, $\sigma$ formed very rapidly with respect to what is typical for stainless steels. It was suggested that enhanced diffusion of $V$ into the steel locally at the interface due to local melting increased the rate at which $\sigma$ forms during cooling. Small, discrete intermetallic particles were seen at the interfaces of $\mathrm{V}$ co-extruded with 21-6-9, type 304 and SANDVIK SAF 2205 stainless steels. After heat treatment, these particles grew into continuous layers about 10-20 $\mu \mathrm{m}$ thick. Based on the appearance, composition and hardness of this interfacial phase, it was also concluded to be the $\sigma$ phase. It appears, then that $\mathrm{V}$ is a potent $\sigma$ former even in the solid state although it does not form as rapidly during co-extrusion as in inertia friction welding probably due to the lack of localized melting at the interface during co-extrusion. Carbides formed at the interface of $\mathrm{V}$ and type 430 stainless steel during co-extrusion due to the higher $\mathrm{C}$ content of this steel and the rather high affinity of $\mathrm{V}$ for $\mathrm{C}$.

The concentricity of the V and stainless steel tubing appears to be fairly good in both the co-extruded and co-hipped samples with the hipping process producing slightly more concentric tubes. Following hipping, however, a continuous $\sigma$ layer is present along the interface. Due to its extreme brittleness, this interfacial layer is quite likely to crack if any further processing of the tubing is required. Even in the co-extruded samples, $\sigma$ or carbide particles which might nucleate interfacial failure during subsequent processing 
operations are present along the $\mathrm{V} / \mathrm{steel}$ interfaces. It was also shown that thermal straining took place in the $\mathrm{V}$ due to thermal expansion coefficient mismatches across the interface particularly in the 21-6-9 and SANDVIK SAF 2205 stainless steels. It is possible that these thermal strains may present a problem during any heating operations especially if a brittle interfacial phase is present and in actual tubes which would be longer than those studied here.

Acknowledgement. The author wishes to acknowledge M. Wall who did the TEM work, i.e. sample preparation, microscopy and electron diffraction analysis, presented in this report. Also, the technical discussions with and work in the initial stages of this project done by J. Hanafee and D. Kautz are appreciated, and contributions of D. McCoy to the microprobe analysis were invaluable in determining the interface structure in these specimens.

\section{REFERENCES}

1. D. Peckner and I.M. Bernstein, Handbook of Stainless Steels, McGraw-Hill Book Company (1977).

2. S. Bukovinsky, H. Gripenberg, U. Lundell and M. Tynell, "SANDVIK SAF 2205 - a High-Performance Ferritic-Austenitic Stainless Steel," SANDVIK Steel Report \#S-51-26-ENG.

3. E.O. Hall and S.H. Algie, "The Sigma Phase," Metallurgical Reviews," 11 (1966), 61-88.

4. W. Rostoker and A. Yamamoto, "A Survey of Vanadium Binary Systems," Trans. ASM, $\underline{46}$ (1954), 1136-1167.

5. J.S. Kasper and R.M. Waterstrat, "Ordering of Atoms in the $\sigma$ Phase," Acta Cryst., 2 (1956), 289-295.

6. H.L. Yakel, "Atom Distributions in Sigma Phases. I. Fe and Cr Atom Distributions in a Binary Sigma Phase Equilibrated at 1063, 1013 and 923K," Acta Cryst., B39 (1983), 20-28.

7. Y.S. Touloukian, R.K. Kirby, R.E. Taylor and P.D. Desai, Thermophysical Properties of Matter, Volume 12, "Thermal Expansion: Metallic Elements and Alloys," IFI/Plenum Data Company, New York (1977).

8. G.V. Raynor and V.G. Rivlin, Phase Equilibria in Iron Ternary Alloys, The Institute of Metals (1988).

9. V.P. Gavrilyuk, L. V. Khaustova and E.A. Markovskii, "Change in Structure of an Iron-Chromium Alloy During Service," Institute of Problems of Casting, Academy 
of Sciences of the Ukrainian SSR. Translated from Metallovedenie i Termicheskaya Obrabotka Metallov, No. 1 (January, 1985), 29-30.

10. T. Naohara and K. Shinohara, "Mechanism of Sigma Formation in an Equiatomic Fe-V Alloy," Transactions of the Japan Institute of Metals, 28, \#4 (1987), 273-280. 
a)

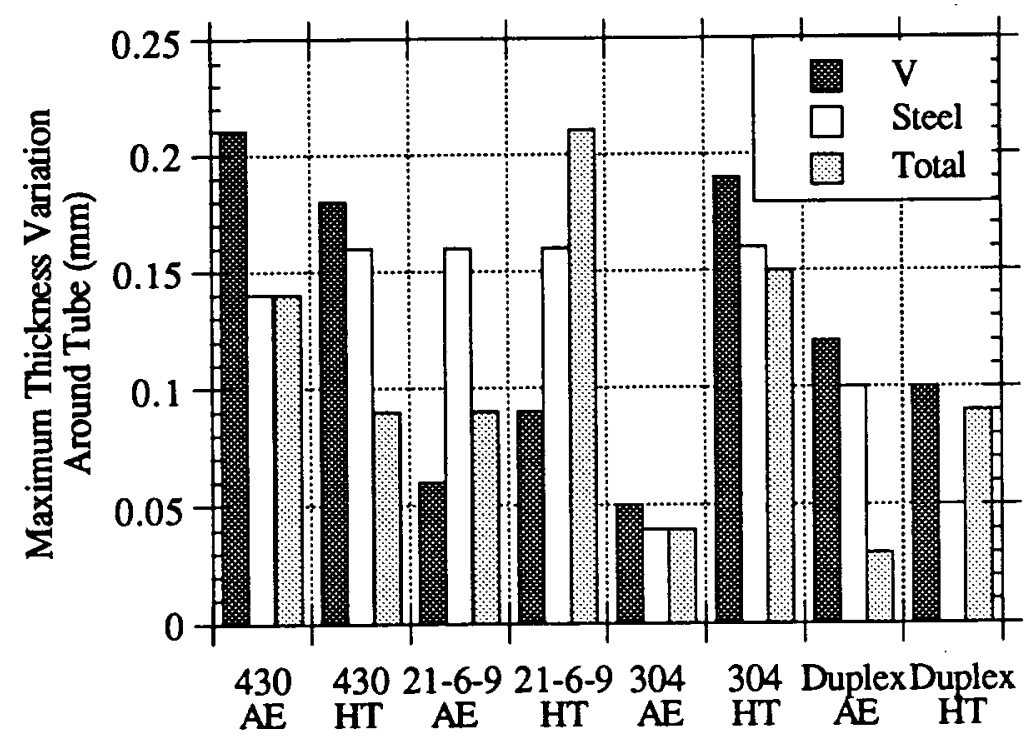

b)

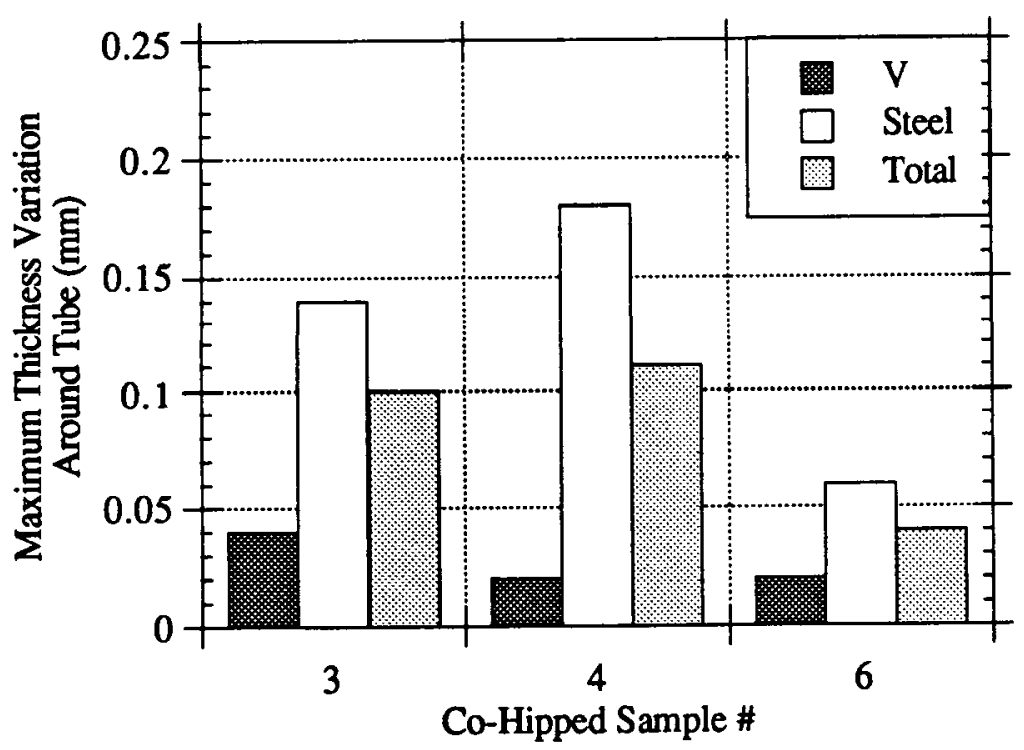

Figure 1. Maximum difference in the $\mathrm{V}$ tube thickness or rod diameter and stainless tube and total thicknesses measured at eight positions around the a) co-extruded and b) co-hipped tubes from photographs taken at a magnification of 12.8 . 


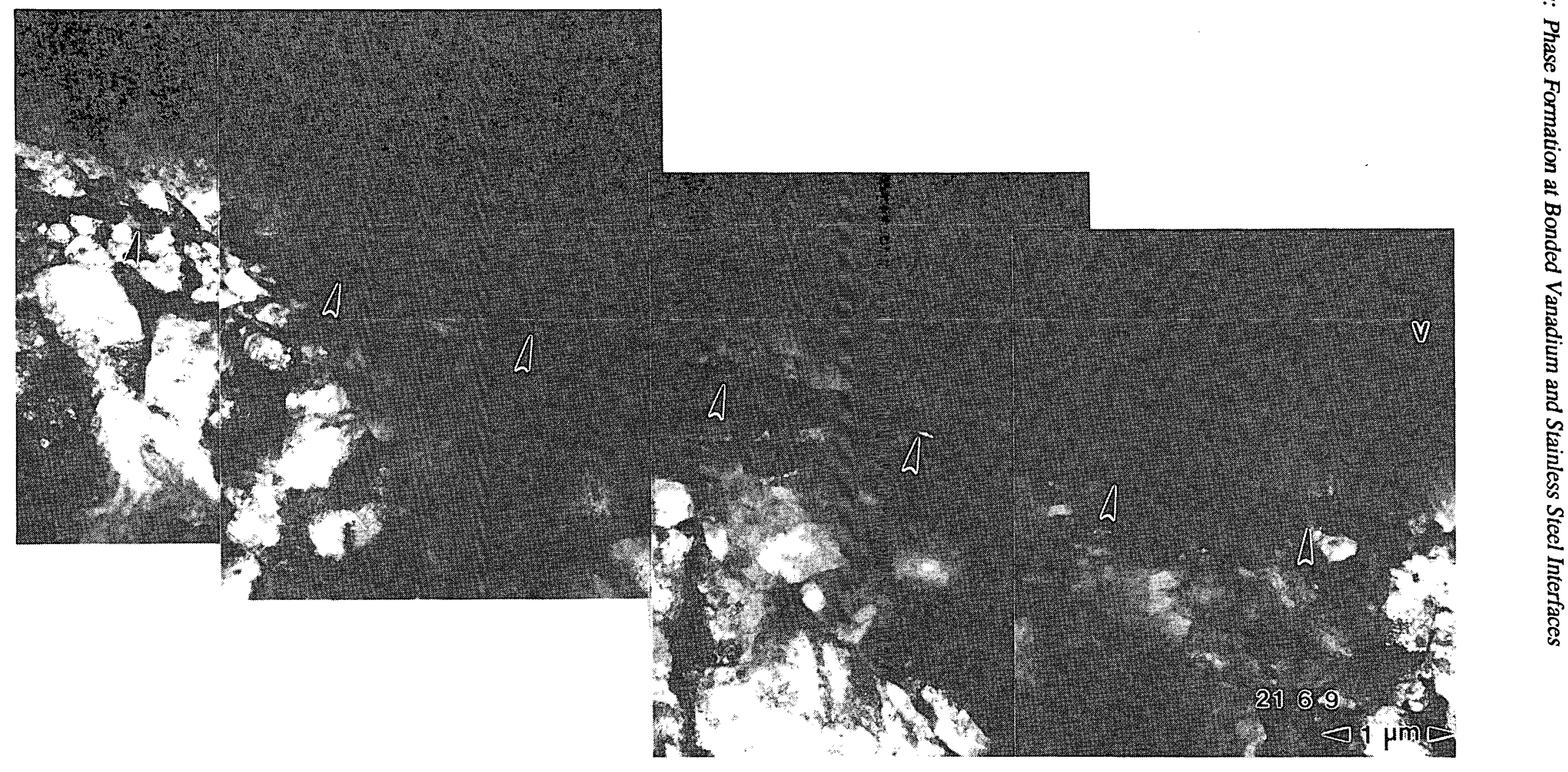

Figure 2. TEM cross section of inertia friction welded vanadium and 21-6-9 stainless steel. A continuous $\sigma$ layer exists at the interface in the as-welded condition. (Micrograph courtesy M. Wall) 

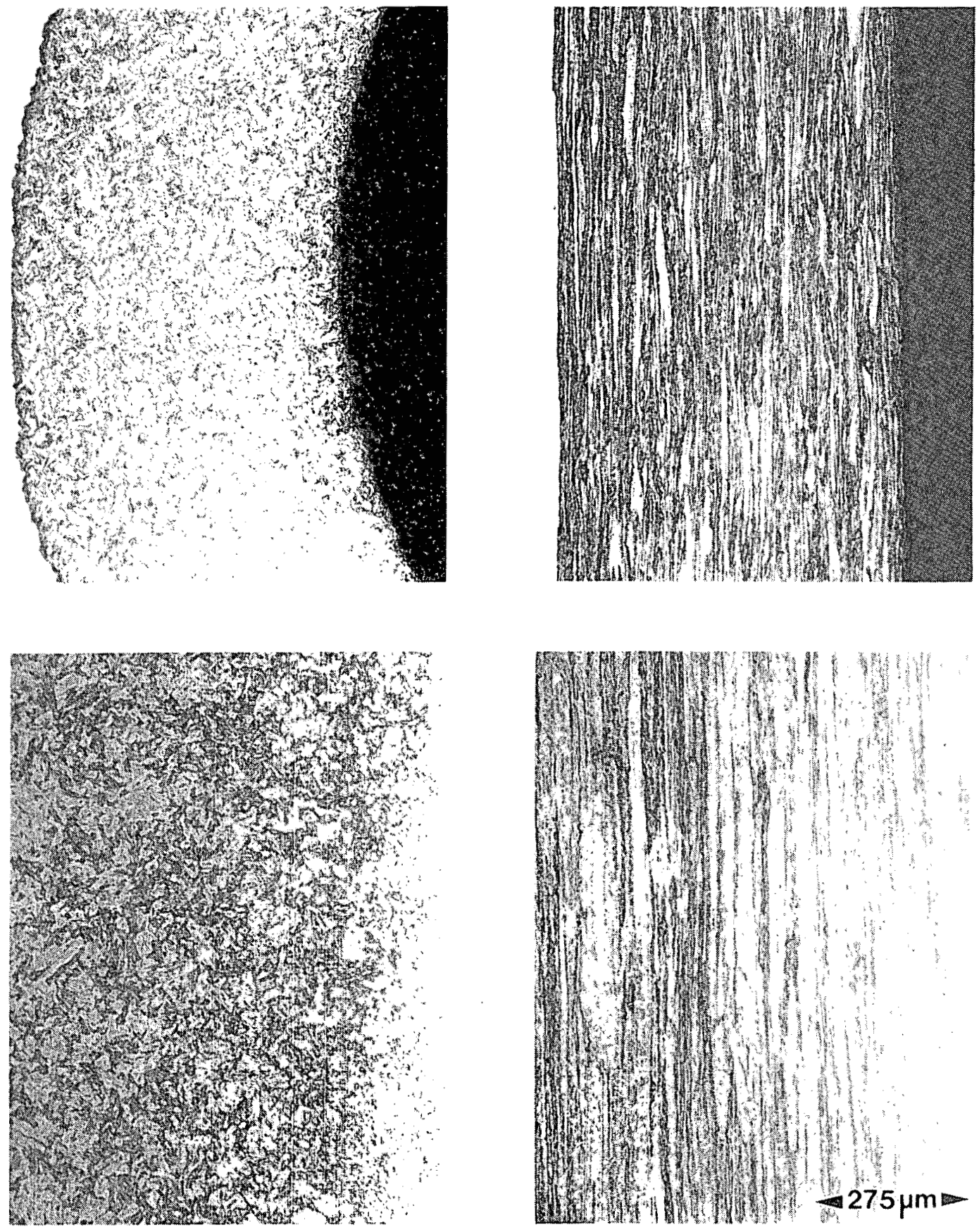

Figure 3. Typical microstructures from the as-extruded specimens in transverse (left) and longitudinal (right) cross sections taken in the vanadium (top) and steel (bottom) regions. 

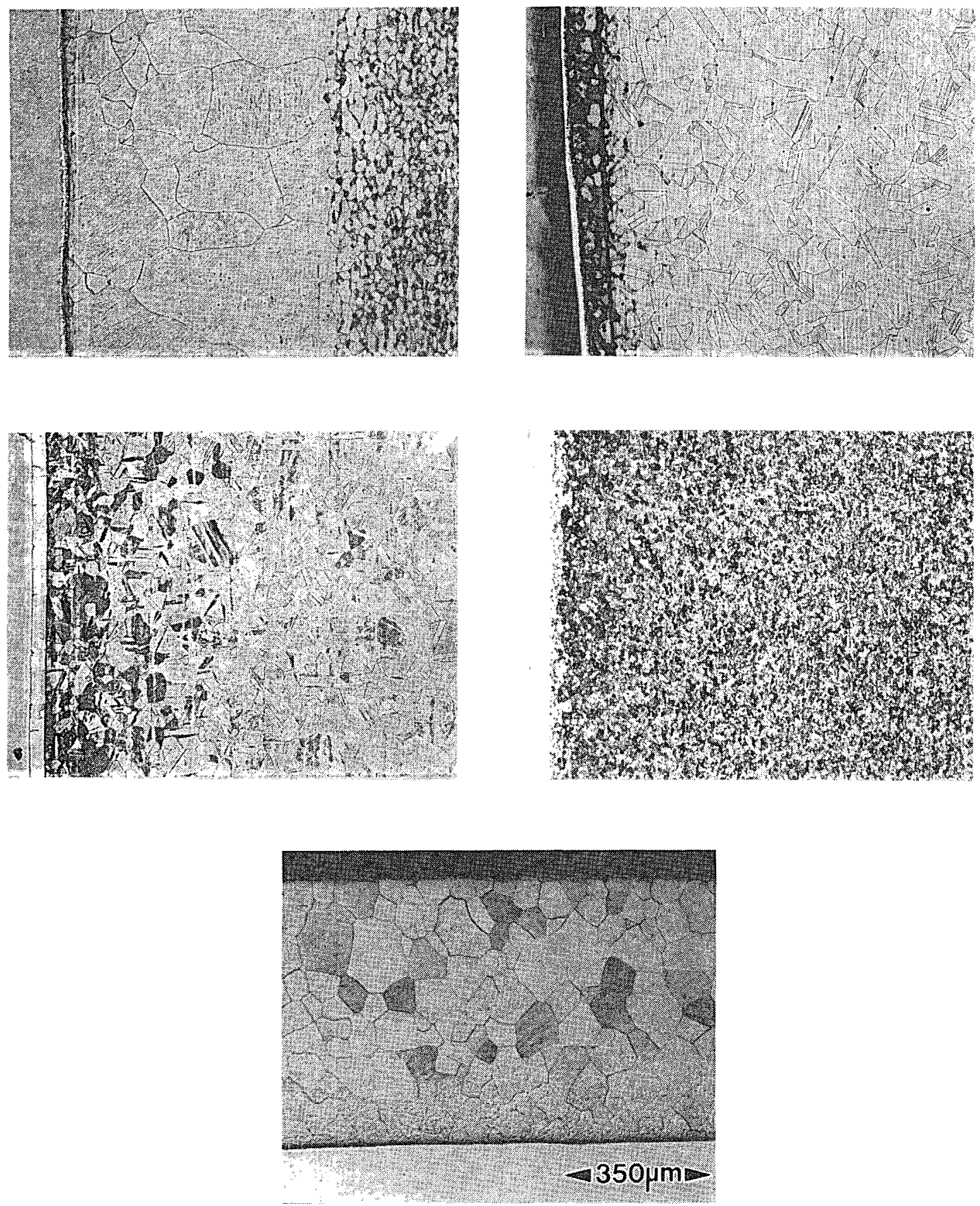

Figure 4. Typical microstructures of the type 430 (top left), 21-6-9 (top right), type 304 (middle left) and duplex (middle right) stainless steels co-extruded with $\mathrm{V}$ and heat treated for two hours at $1000^{\circ} \mathrm{C}$. The typical V microstructure following heat treatment is shown at the bottom. 

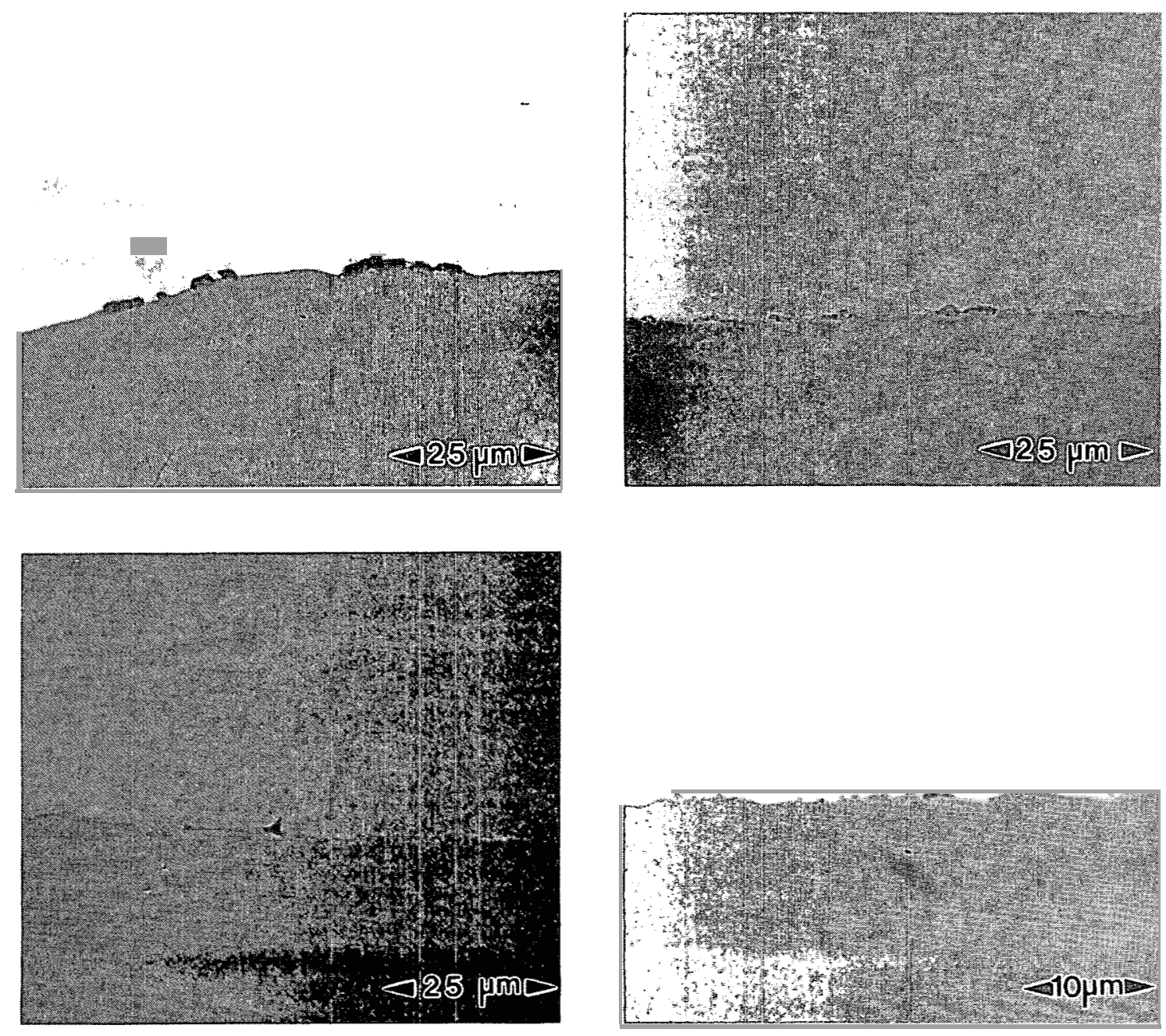

Figure 5. Interfacial particles present following co-extrusion of $\mathrm{V}$ and type 430 (top left), 21-6-9 (top right), type 304 (bottom left) and a duplex (bottom right) stainless steel. 

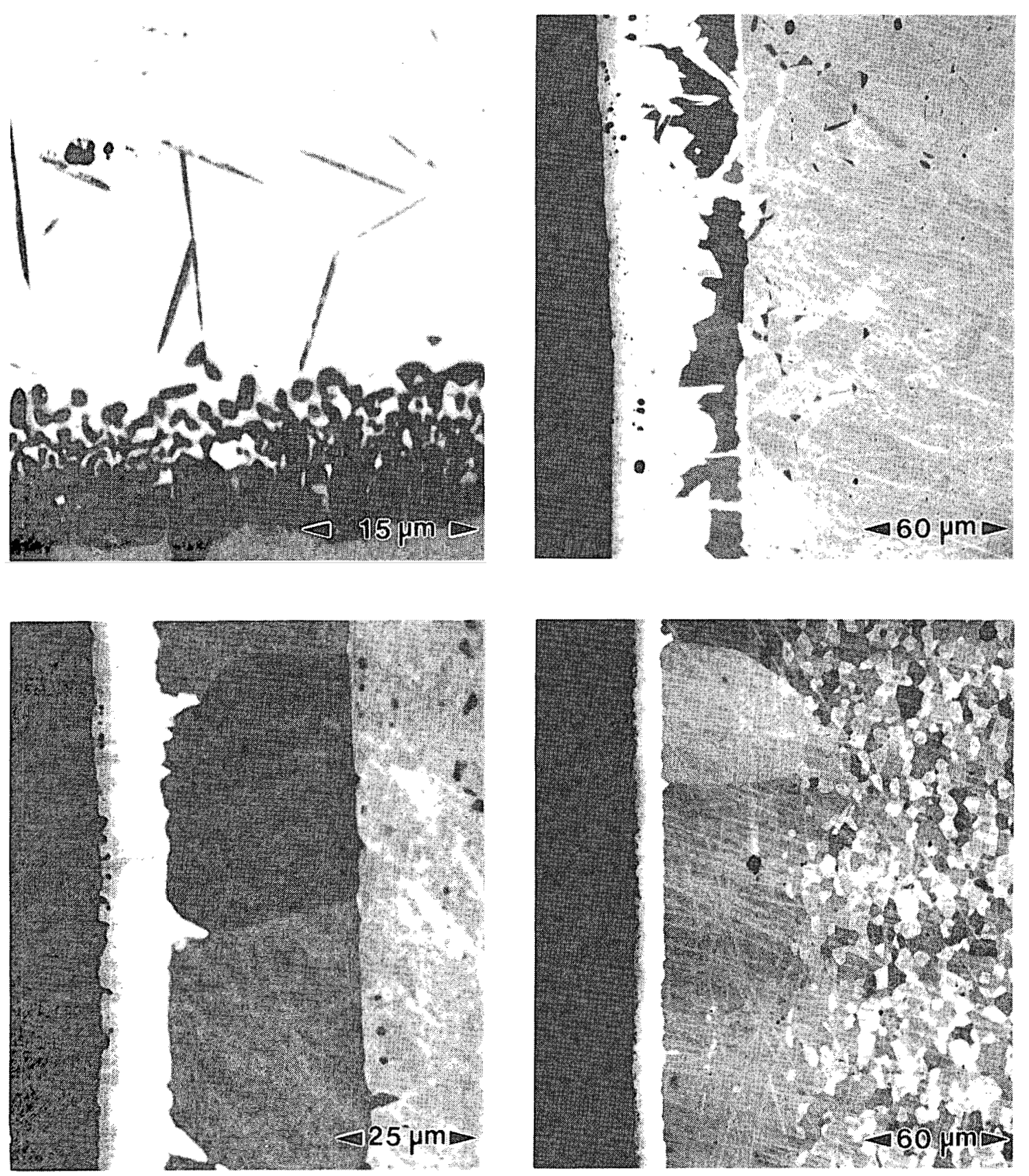

Figure 6. Interface structures present following co-extrusion of $\mathrm{V}$ and type 430 (top left), 21-6-9 (top right), type 304 (bottom left) and a duplex (bottom right) stainless steel and heat treatment at $1000^{\circ} \mathrm{C}$ for 2 hours. 

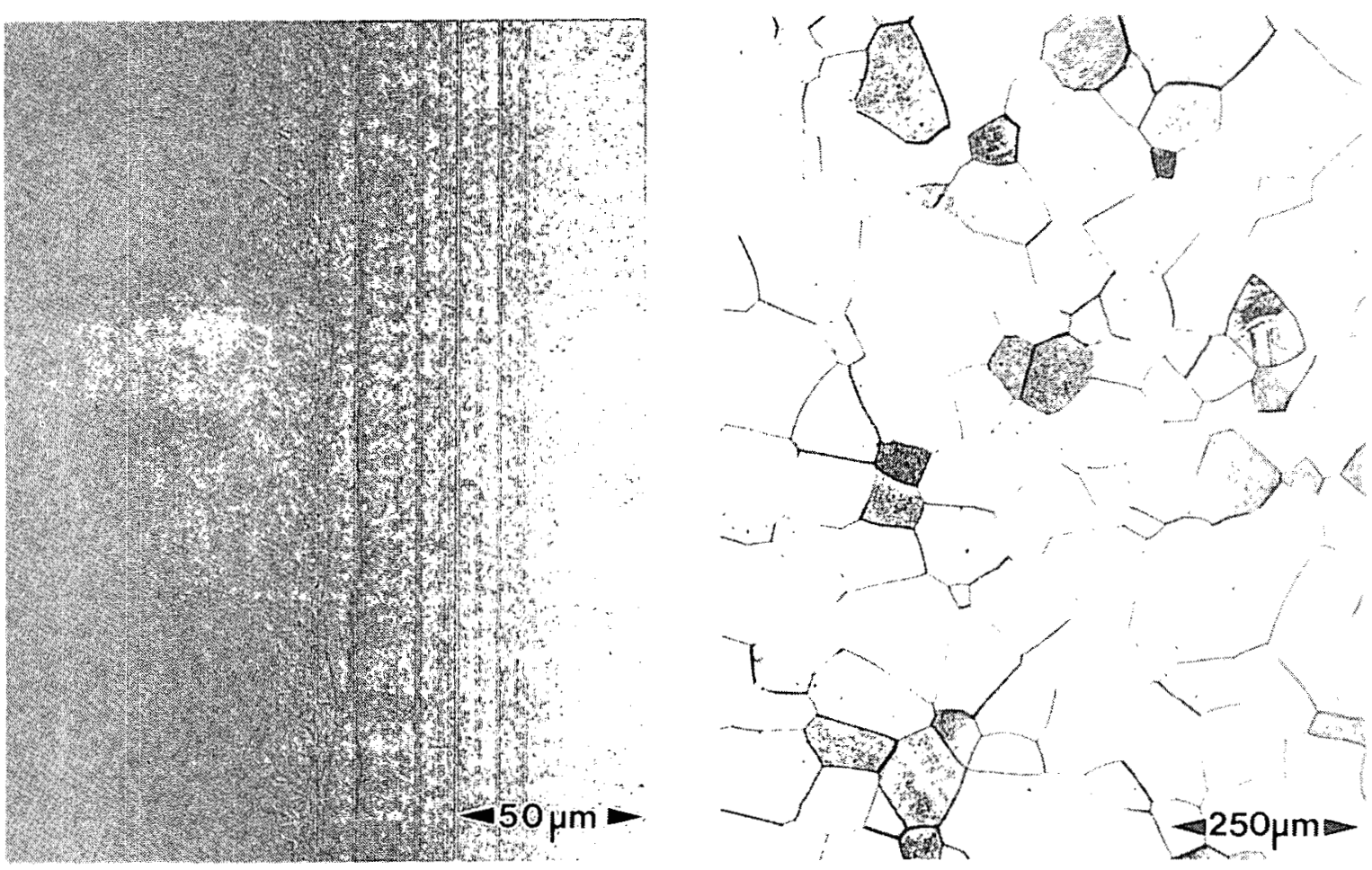

Figure 7. Optical micrograph of co-hipped $V$ and 21-6-9 stainless steel interface (left) and $V$ (right) in the as-hipped condition.
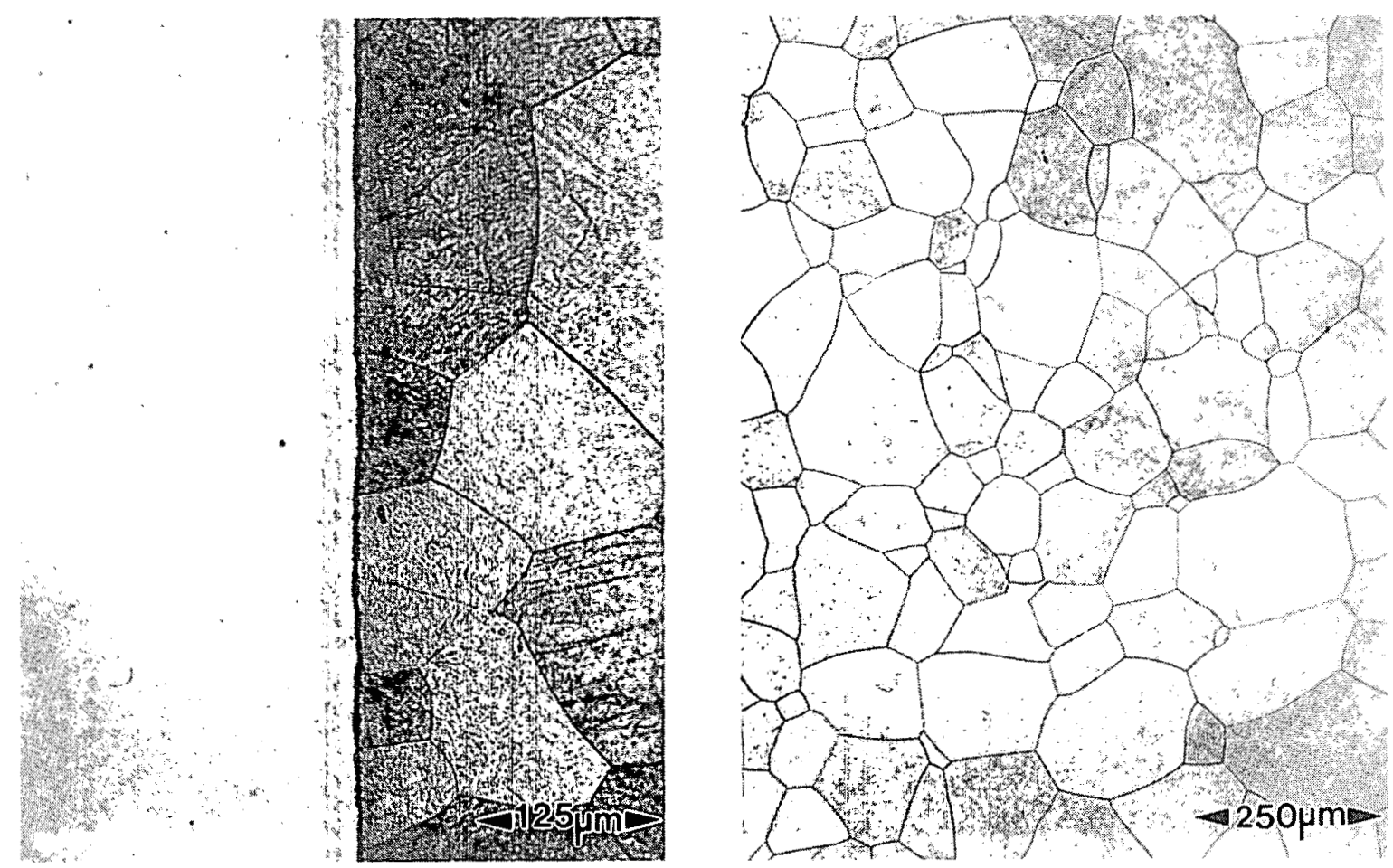

Figure 8. Optical micrograph of co-hipped $V$ and 21-6-9 stainless steel interface (left) and $\mathrm{V}$ (right) following heat treatment at $1000^{\circ} \mathrm{C}$ for 2 hours. 

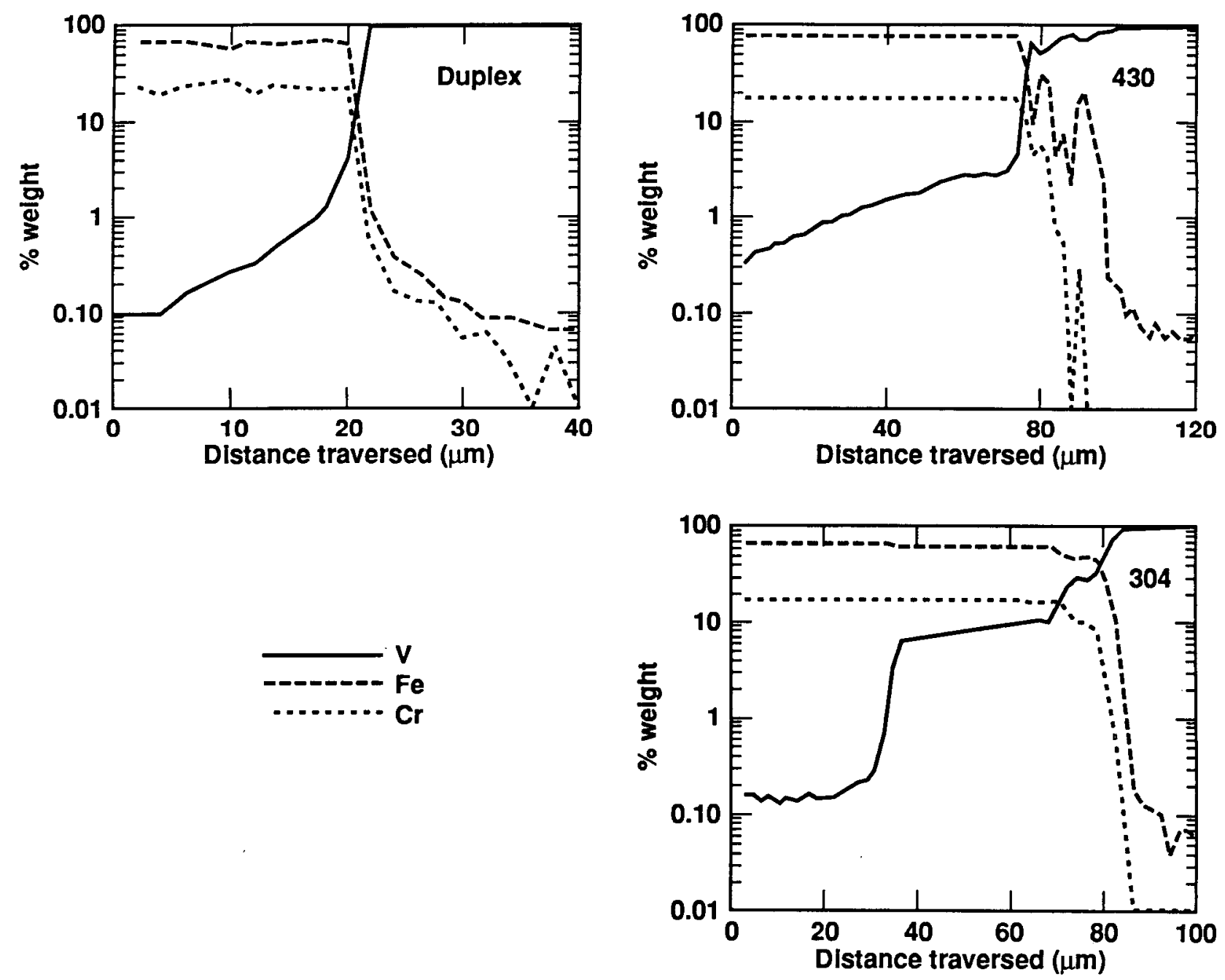

Figure 9. Representative Microprobe traces across the V/stainless steel interfaces for a) as-extruded samples, b) heat treated type 430 and duplex stainless steels and c) heat treated austenitic type 304 and 21-6-9 stainless steels. 

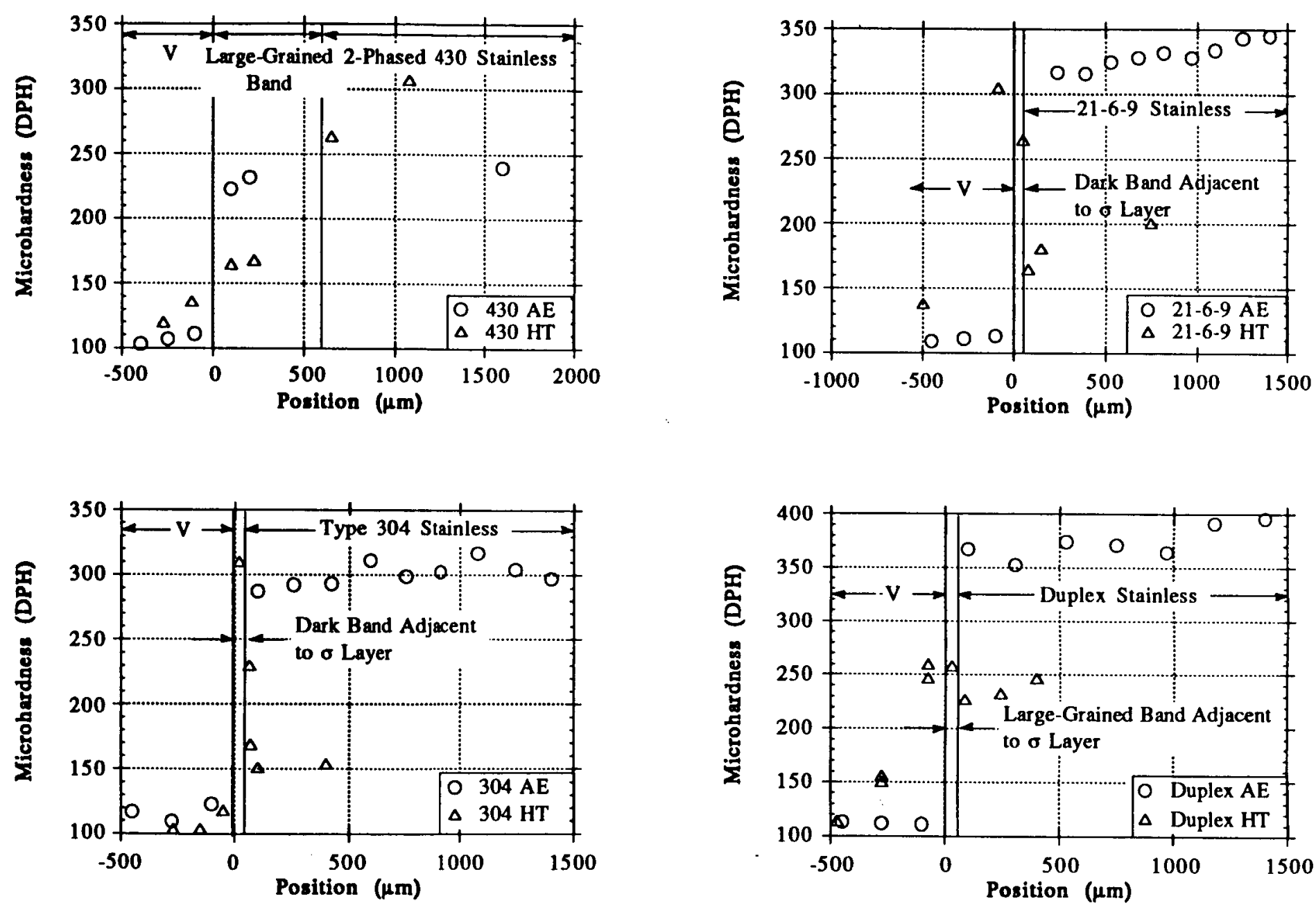

Figure 10. Microhardness traces across the longitudinal interfaces between $\mathrm{V}$ and the four stainless steels bonded by a co-extrusion process. Positive positions correspond to positions in the stainless steel and negative positions correspond to the vanadium. Labelled regions on the graphs refer to the heat treated (HT) microstructures of Figures 4 and 6 . The hardness of the interfacial layer (carbide or $\sigma$ phase) in the heat treated samples is not included in the plot. 

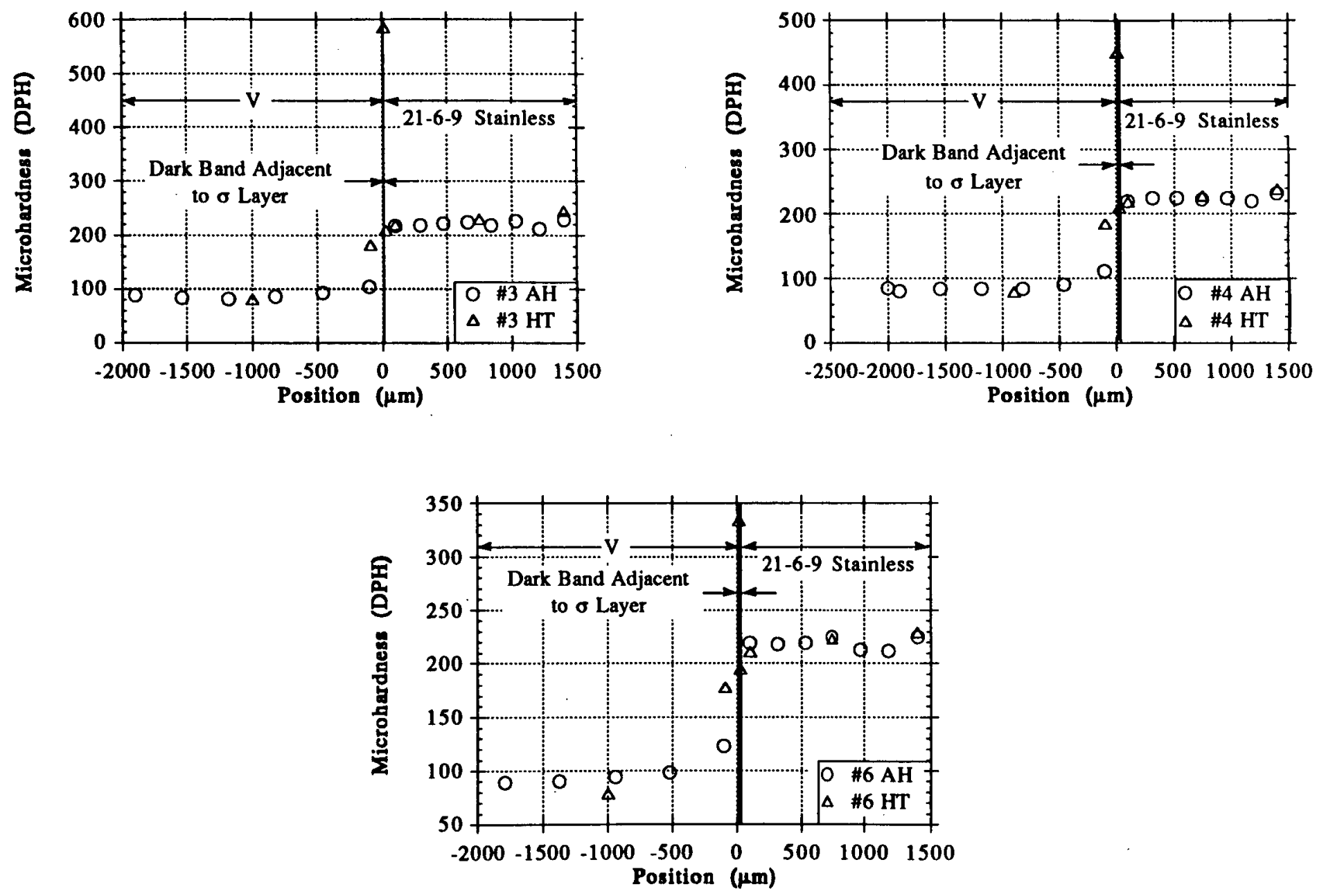

Figure 11. Microhardness traces across the longitudinal interface between $V$ and 21-6-9 stainless steels bonded by co-hipping. Positive positions correspond to positions in the stainless steel and negative positions correspond to the vanadium. Labelled regions on the graphs refer to the heat treated (HT) microstructures of Figure 8. The hardness of the interfacial layer ( $\sigma$ phase) in the heat treated samples is not included in the plot. 


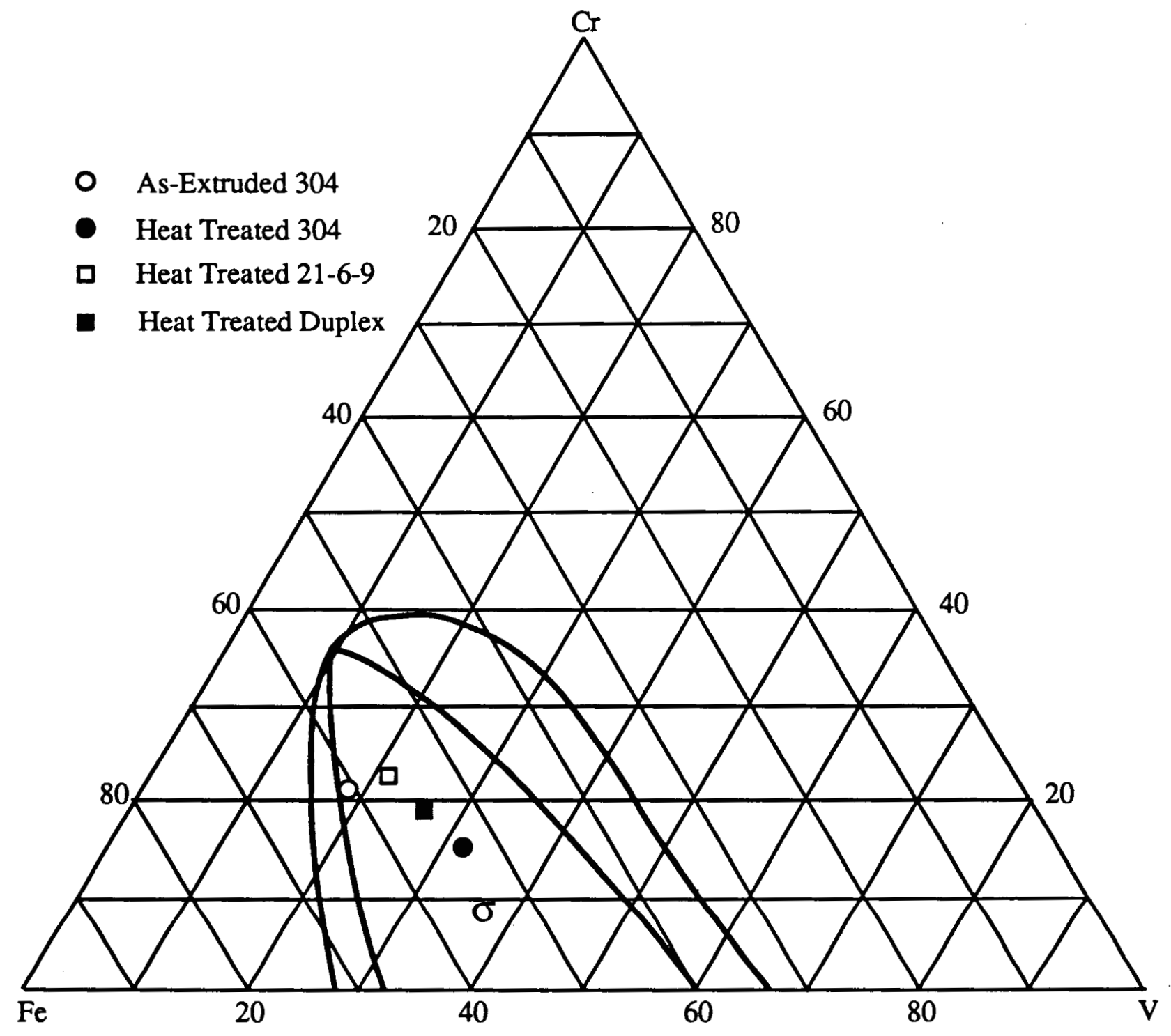

Figure 12. The $900^{\circ} \mathrm{C}$ isotherm of the $\mathrm{Cr}-\mathrm{Fe}-\mathrm{V}$ phase diagram. The $\sigma$-phase compositions measured by microprobe are plotted for the four cases where $\mathrm{Cr}$, $\mathrm{Fe}$ and $\mathrm{V}$ are the major elements present (adapted from [8]). 


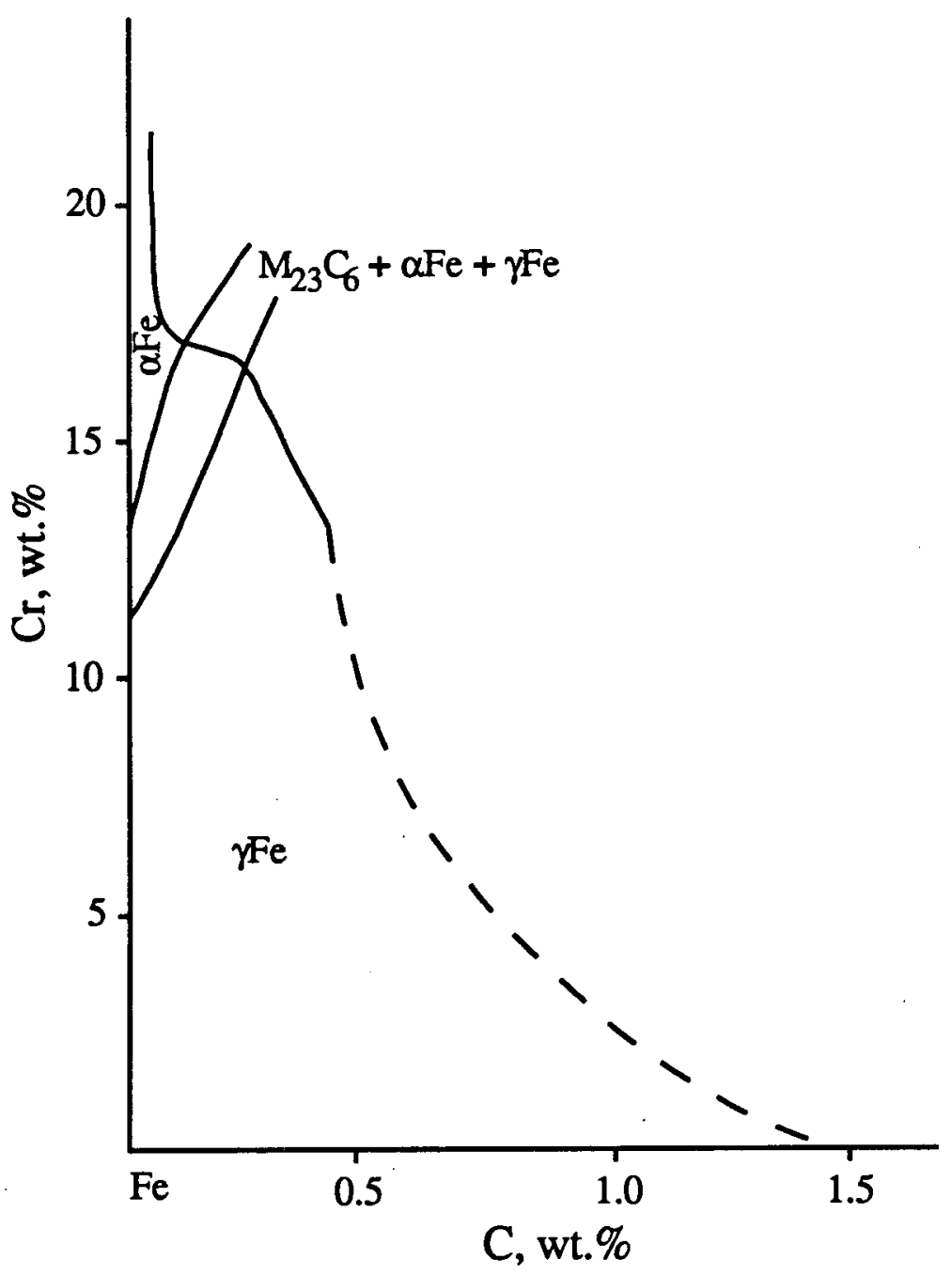

Figure 13. The Fe-rich region of the $\mathrm{C}-\mathrm{Cr}$-Fe phase diagram at $1000^{\circ} \mathrm{C}$ (adapted from [8]). 


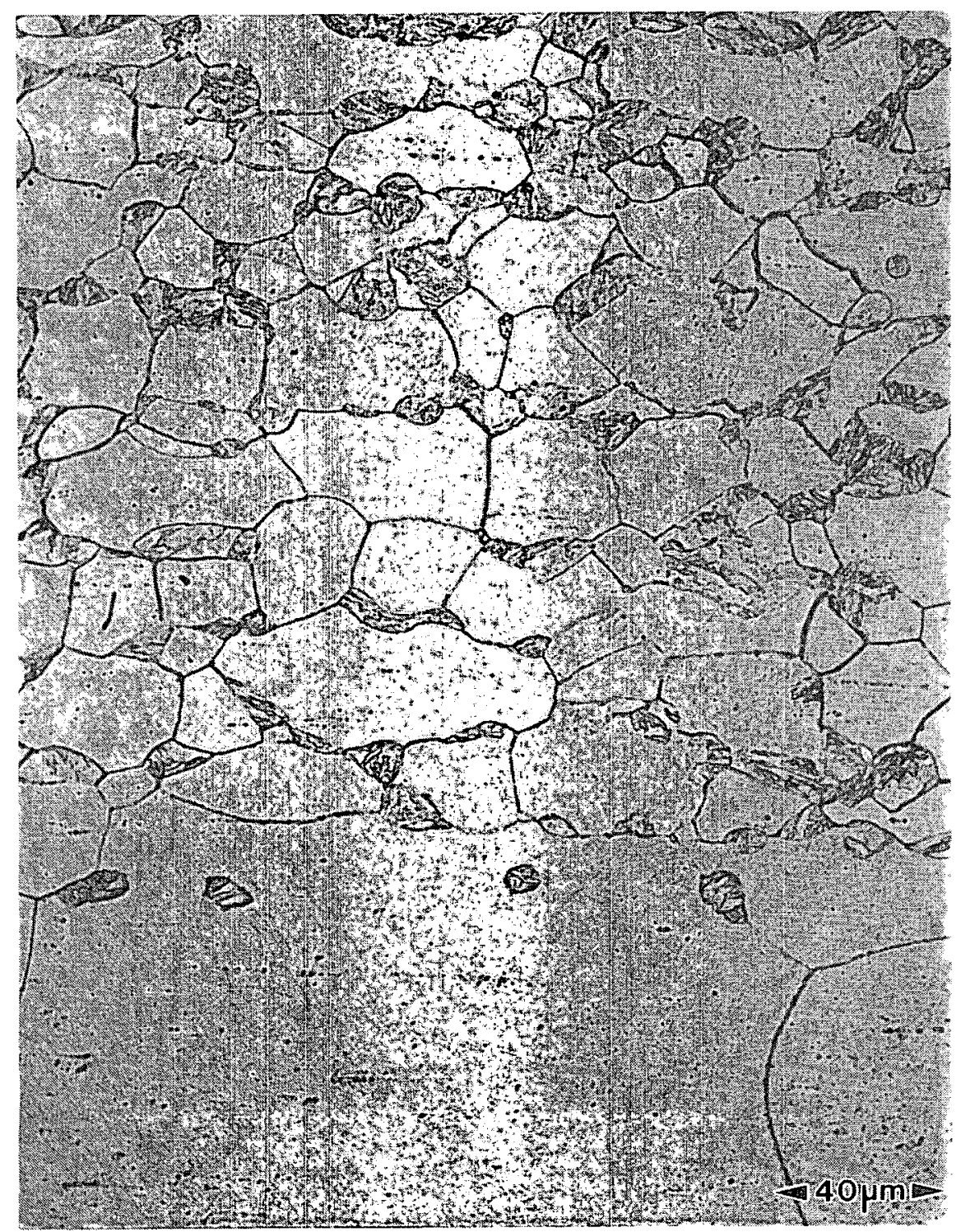

Figure 14. Optical micrograph of the type 430 stainless steel microstructure in the coextruded specimen at the outer edge of the large-grained, single-phase band following heat treatment at $1000^{\circ} \mathrm{C}$ for 2 hours. The darker grains appear to be composed of two phases which are probably ferrite and some carbide which formed from the austenite present at $1000^{\circ} \mathrm{C}$. 


\section{APPENDIX}

The interface between $V$ and 21-6-9 stainless steel bonded by inertia friction welding was examined in the as-welded condition and after heat treatment at $1200^{\circ} \mathrm{C}$ for 2 hours in a TEM. A sample indexed diffraction pattern is given below in Figure A1, and the corresponding measured interatomic spacings are given in Table A1. The spacings calculated using the lattice parameter for the $\sigma$ phase and the indeces found are given for comparison.

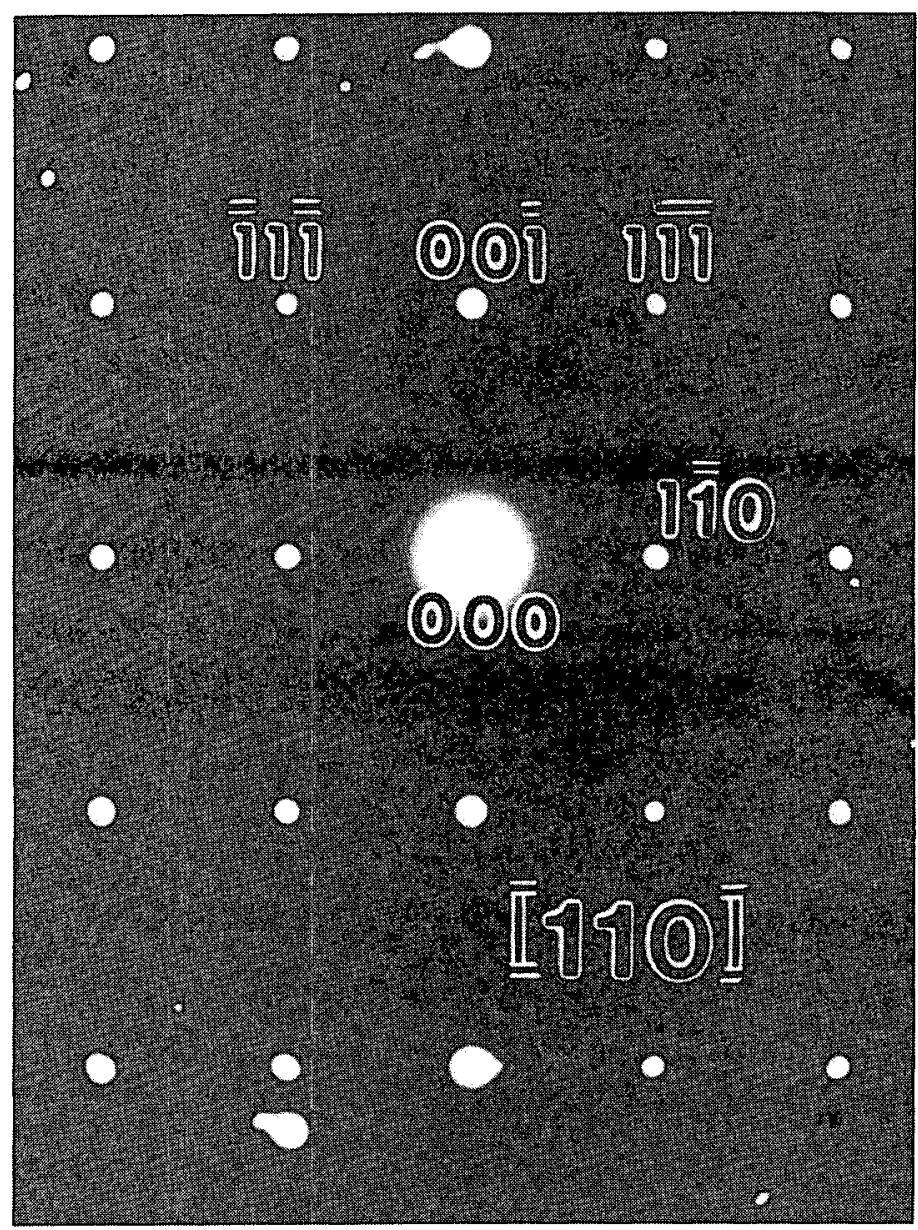

Figure A1. The [110] diffraction pattern taken from the $\sigma$ phase along the interfacial boundary of $V$ and 21-6-9 stainless steel bonded by inertia friction welding.

Table A1

Interatomic Spacings $(\AA)$ for the Diffraction Pattern indexed in Figure A1

\begin{tabular}{|c|c|c|}
\hline hkl & Measured & Calculated \\
\hline \hline $1 \overline{1} 0$ & 6.28 & 6.22 \\
\hline $00 \overline{1}$ & 4.54 & 4.54 \\
\hline $1 \overline{1} \overline{1}$ & 3.70 & 3.67 \\
\hline
\end{tabular}


